Article

\title{
Description of Three Novel Members in the Family Geobacteraceae, Oryzomonas japonicum gen. nov., sp. nov., Oryzomonas sagensis sp. nov., and Oryzomonas ruber sp. nov.
}

\author{
Zhenxing Xu ${ }^{1}$, Yoko Masuda ${ }^{1, *} *$, , Chie Hayakawa ${ }^{2}$, Natsumi Ushijima ${ }^{3}$, Keisuke Kawano ${ }^{4,+}$, \\ Yutaka Shiratori ${ }^{5}$, Keishi Senoo ${ }^{1,6}$ and Hideomi Itoh ${ }^{7, *}$ \\ 1 Department of Applied Biological Chemistry, Graduate School of Agricultural and Life Sciences, \\ The University of Tokyo, Tokyo 113-8657, Japan; xuzx.ut@gmail.com (Z.X.); \\ asenoo@mail.ecc.u-tokyo.ac.jp (K.S.) \\ 2 School of Agriculture, Utsunomiya University, Tochigi 321-8505, Japan; chayakawa@cc.utsunomiya-u.ac.jp \\ 3 Support Section for Education and Research, Graduate School of Dental Medicine, Hokkaido University, \\ Hokkaido 060-8586, Japan; ntm@den.hokudai.ac.jp \\ 4 Department of Marine Biology and Sciences, School of Biological Sciences, Tokai University, \\ Hokkaido 005-8601, Japan; kawano.1021@aist.go.jp \\ 5 Niigata Agricultural Research Institute, Niigata 940-0826, Japan; sira@ari.pref.niigata.jp \\ 6 Collaborative Research Institute for Innovative Microbiology, The University of Tokyo, Tokyo 113-8657, Japan \\ 7 Bioproduction Research Institute, National Institute of Advanced Industrial Science and Technology (AIST) \\ Hokkaido, Hokkaido 062-8517, Japan \\ * Correspondence: ygigico@gmail.com (Y.M.); hideomi-itou@aist.go.jp (H.I.) \\ + Present address: Division of Agriculture, Graduate School of Agriculture, Hokkaido University, \\ Hokkaido 060-8589, Japan.
}

Received: 17 March 2020; Accepted: 25 April 2020; Published: 27 April 2020

\begin{abstract}
Bacteria of the family Geobacteraceae are particularly common and deeply involved in many biogeochemical processes in terrestrial and freshwater environments. As part of a study to understand biogeochemical cycling in freshwater sediments, three iron-reducing isolates, designated as Red96 ${ }^{\mathrm{T}}$, Red $100^{\mathrm{T}}$, and Red $88^{\mathrm{T}}$, were isolated from the soils of two paddy fields and pond sediment located in Japan. The cells were Gram-negative, strictly anaerobic, rod-shaped, motile, and red-pigmented on agar plates. Growth of these three strains was coupled to the reduction of $\mathrm{Fe}(\mathrm{III})-\mathrm{NTA}, \mathrm{Fe}$ (III) citrate, and ferrihydrite with malate, methanol, pyruvate, and various organic acids and sugars serving as alternate electron donors. Phylogenetic analysis based on the housekeeping genes (16S rRNA gene, gyrB, rpoB, nifD, fus $A$, and $r e c A$ ) and 92 concatenated core genes indicated that all the isolates constituted a coherent cluster within the family Geobacteraceae. Genomic analyses, including average nucleotide identity and DNA-DNA hybridization, clearly differentiated the strains Red $96^{\mathrm{T}}, \operatorname{Red}_{100^{\mathrm{T}}}$, and $\operatorname{Red} 88^{\mathrm{T}}$ from other species in the family Geobacteraceae, with values below the thresholds for species delineation. Along with the genomic comparison, the chemotaxonomic features further helped distinguish the three isolates from each other. In addition, the lower values of average amino acid identity and percentage of conserved protein, as well as biochemical differences with their relatives, indicated that the three strains represented a novel genus in the family Geobacteraceae. Hence, we concluded that strains $\operatorname{Red} 96^{\mathrm{T}}, \operatorname{Red} 100^{\mathrm{T}}$, and $\operatorname{Red} 88^{\mathrm{T}}$ represented three novel species of a novel genus in the family Geobacteraceae, for which the names Oryzomonas japonicum gen. nov., sp. nov., Oryzomonas sagensis sp. nov., and Oryzomonas ruber sp. nov. are proposed, with type strains Red $96^{\mathrm{T}}$ $\left(=\right.$ NBRC $114286^{\mathrm{T}}=$ MCCC $\left.1 K 04376^{\mathrm{T}}\right), \operatorname{Red}_{100}{ }^{\mathrm{T}}\left(=\mathrm{NBRC} 114287^{\mathrm{T}}=\right.$ MCCC $\left.1 \mathrm{~K} 04377^{\mathrm{T}}\right)$, and Red88 ${ }^{\mathrm{T}}$ $\left(=\right.$ MCCC $\left.1 K 03694^{\mathrm{T}}=\mathrm{JCM} 33033^{\mathrm{T}}\right)$, respectively.
\end{abstract}


Keywords: Oryzomonas japonicum sp. nov.; Oryzomonas sagensis sp. nov.; Oryzomonas ruber sp. nov.; Geobacteraceae; paddy soil; pond sediment; iron-reducing bacteria

\section{Introduction}

The family Geobacteraceae, belonging to the order Desulfuromonadales, is described as consisting of the genera Geobacter, Geomonas, and a single species Pelobacter propionicus [1,2]. Among them, the type genus Geobacter, which was first described by Lovley et al. [3] with Geobacter metalireducens as the type species, is the most major group, including 17 validated species at the time of writing (Available online: http://www.bacterio.net/geobacter.html). These species are mesophilic and obligate anaerobes, which were usually isolated from terrestrial environments such as forest soil, lotus field mud, freshwater sediments, and oil/metal-contaminated soils [4-6]. In addition to the culture-based explorations, the DNA- and RNA-based culture-independent analysis also supports the universal distribution of Geobacter in the soils and freshwater sediments [7-9]. A common feature among the members of genus Geobacter is the ability to reduce Fe(III) to Fe(II) along with the complete oxidation of acetate to $\mathrm{CO}_{2}$. Additionally, they can utilize various metals, humic substances, alcohols, hydrogen, organic acids, and aromatic compounds as electron acceptors and/or electron donors, leading to mobilization of metals and mineralization of organic compounds [4]. The ubiquitous distribution and metabolic properties of Geobacter species suggest their importance in the biogeochemical cycle of both inorganic and organic materials in the terrestrial and freshwater ecosystems.

Especially in paddy soils, the distribution and predominance of Geoobacteraceae, especially Geobacter, are reported globally [10-14]. At the beginning of cultivation, paddy fields are waterlogged. Immediately after that, soil redox potential decreases, and an anoxic environment develops within the plowed layer of soil [11]. Such condition induces various biogeochemical processes such as metal reductions, reductive nitrogen transformations, and methanogenesis [11]. Previous studies based on stable-isotope probing and high throughput sequencing, have suggested that Geobacteraceae, which dominates in paddy soils, is one of the major drivers directly involved in Fe(III) reduction along with acetate oxidation, nitrogen fixation, dissimilatory nitrate reduction to ammonium (DNRA), and anaerobic ammonium oxidation coupled to Fe(III) reduction (Feammox) and indirectly involved in methanogenesis [8,13,15-18]. However, limited information is available about the isolation of Geobacteraceae strains from paddy soils despite its predominance and pivotal ecological functions [16,19,20], and no paddy soil-derived validated species have been reported except for the genus Geomonas, which was recently proposed in our previous study [2]. Although freshwater sediments have prolonged waterlogged conditions unlike paddy soils, our previous study suggests that Geobacter is one of the major microbial drivers of the nitrogen cycle in freshwater sediments, as well as paddy soils [13]. However, there are fewer Geobacter strains isolated from freshwater sediments compared with microbes involved in the nitrogen cycle, such as nitrogen fixers in other genera [21]. Therefore, we focused on Geobacteraceae dominating in paddy soils and freshwater sediments, and try to expand the cultured strains for future studies based on genomics and culturomics [22].

During the screening from paddy soils and the related environments, via the soil slurry incubation as described below, three Geobacteraceae strains named $\operatorname{Red} 96^{\mathrm{T}}$, $\operatorname{Red} 100^{\mathrm{T}}$, and $\operatorname{Red} 88^{\mathrm{T}}$ were isolated from two paddy fields and pond sediment, respectively. Comparative 16S rRNA gene sequencing demonstrated that these three novel strains may represent a new taxon of the family Geobacteraceae. Therefore, the present study was carried out to define the taxonomy of these three strains through polyphasic characterization. 


\section{Materials and Methods}

\subsection{Isolation and Culture Conditions}

The strains $\operatorname{Red} 6^{\mathrm{T}}$ and Red100 ${ }^{\mathrm{T}}$ were isolated from paddy soils in Nagaoka, Niigata, Japan, and Kanzaki, Saga, Japan, respectively (Figure S1). The strain Red $88^{\mathrm{T}}$ was isolated from the pond sediment in Nagaoka, Niigata, Japan (Figure S1). For the isolation of these strains, we applied the following method based upon soil slurry incubation. The air-dried paddy soil, which was collected from the paddy fields in Nagaoka, Niigata, Japan, was suspended in distilled water (soil/water, 1/1.5, $w / v)$, and $6 \mathrm{~mL}$ of the resulting soil suspension was transferred to a $15 \mathrm{~mL}$ serum bottle. The serum bottle was then autoclaved, and $60 \mu \mathrm{l}$ of Wolfe's vitamin solution (in $\mathrm{l}^{-1}$, $10 \mathrm{mg}$ pyridoxine- $\mathrm{HCl}, 5 \mathrm{mg}$ thiamine- $\mathrm{HCl}, 5 \mathrm{mg}$ aminobenzoic acid, $5 \mathrm{mg}$ lipoic acid, $5 \mathrm{mg}$ Ca-pantothenate, $5 \mathrm{mg}$ nicotinic acid, $2 \mathrm{mg}$ biotin, $2 \mathrm{mg}$ folic acid, and $0.01 \mathrm{mg}$ vitamin $\mathrm{B}_{12}$ ) was added. These bottles were sealed with a butyl rubber stopper with an aluminum crimp, and the gaseous phase was exchanged with $\mathrm{N}_{2} / \mathrm{CO}_{2}$ $(4: 1, v / v)$. Into this soil slurry bottle, $0.1 \mathrm{~g}$ raw paddy soil or pond sediment was added as a microbial source and then kept at $30^{\circ} \mathrm{C}$ for 2 weeks. After this incubation, $200 \mu \mathrm{l}$ of the incubated soil suspension was transferred to the fresh soil slurry bottle and cultured at $30^{\circ} \mathrm{C}$ for 2 weeks. The resulting cultures were spread on R2A broth (Nihon Pharmaceutical, Tokyo, Japan) medium supplemented with $1.5 \%$ agar and $5 \mathrm{mM}$ fumarate (modified R2A plate) and incubated in anaerobic jars at $30{ }^{\circ} \mathrm{C}$ for 10 days. The jars were provided with AnaeroPacks (Mistsubishi Gas Chemical, Tokyo, Japan) along with oxygen indicators. After the process was repeated several times, three special isolates, namely $\operatorname{Red} 88^{\mathrm{T}}, \operatorname{Red} 6^{\mathrm{T}}$, and $\operatorname{Red} 100^{\mathrm{T}}$, were discriminated from the others by their red colony color. It was found that these three strains also grew well in modified freshwater medium (MFM) supplemented with $20 \mathrm{mM}$ fumarate as the electron acceptor and $20 \mathrm{mM}$ acetate as the electron donor [2,3]. Cultures were stored at $-80^{\circ} \mathrm{C}$ in MFM supplemented with 10\% (v/v) of DMSO. Geobacter chapellei DSM $13688^{\mathrm{T}}$, obtained from the German Collection of Microorganisms and Cell Cultures (DSMZ), was used as the reference strain throughout the study.

\subsection{Morphological and Physiological Analysis}

The Gram reaction of the three strains was determined using a commercial Gram-staining kit (Sigma, St Louis, MO, USA) according to the manufacturer's instructions. Cell morphology was observed by transmission electron microscopy (TEM, model JEM-1400, JEOL, Tokyo, Japan) using the cells that were grown for 5 days on modified R2A plates at $30^{\circ} \mathrm{C}$. The temperature range for growth was investigated on modified R2A plates at different temperatures $\left(13,16,20,25,30,33,37,40\right.$, and $\left.42{ }^{\circ} \mathrm{C}\right)$. The $\mathrm{pH}$ range for growth was examined between $\mathrm{pH} 4.5$ to 8.5 in increments of $0.5 \mathrm{pH}$ units using $\mathrm{R} 2 \mathrm{~A}$ broth with $20 \mathrm{mM}$ fumarate (modified R2A broth) at $30^{\circ} \mathrm{C}$ supplemented with different $\mathrm{pH}$ buffers (acetic acid/acetate, pH 4.5-5.0; MES (20 mM), pH 5.5-6.5; HEPES (20 mM), pH 7.0-8.0; tricine (20 mM), $\mathrm{pH}$ 8.5-9.5). For $\mathrm{pH}$ stability, all the vials were gassed with helium $(\mathrm{He})$ to reduce the $\mathrm{pH}$ fluctuation caused by $\mathrm{CO}_{2}$. Growth condition was qualitied with $\mathrm{OD}_{600}$ using a spectrophotometer (Jasco V550, Tokyo, Japan) after 3 days of incubation. The effect of $\mathrm{NaCl}$ concentration on growth was investigated on modified R2A plates in the presence of $0 \%$ to $1.0 \%(w / v) \mathrm{NaCl}$ in increments of $0.1 \%$. Electron acceptor and donor utilization tests were performed using oxygen-free MFM with acetate $(10 \mathrm{mM})$ as the electron donor for all electron acceptor tests and Fe(III)-NTA (10 mM) as the electron acceptor for all electron donor tests. The concentrations of tested electron acceptors and donors were utilized as described by Nevin et al. [23]. Cytochrome $c$ analysis was carried out using the whole cells grown in degassed MFM with $20 \mathrm{mM}$ acetate and $10 \mathrm{mM}$ fumarate. The dithionite-reduced minus air-oxidized difference spectrum was generated on a Jasco V550 spectrophotometer [3]. Various enzyme activities of the three isolates and the reference strain were determined using API ZYM strips (bioMérieux, Lyon, France) in accordance with the manufacturer's instructions. Fe(III)-NTA (5 mM) and Fe(III) citrate $(20 \mathrm{mM})$ were used as the substrate to determine the iron reduction curve. The concentration of ferrous 
irons at different culture time was measured using the ferrozine assay at $562 \mathrm{~nm}$ with a Jasco V550 spectrophotometer, as described previously [24].

\subsection{Phylogenetic Analysis}

The nearly complete 16S rRNA genes of the three isolates were amplified and sequenced with the primers 27F/1492R and 27F/926R/1492R, respectively, as previously described by Ashida et al. [25]. The alignments and calculations of similarity values of the almost complete $16 S$ rRNA gene sequences corresponding to three strains were carried out using EZBioCloud's Identify service [26]. The phylogenetic trees were constructed using the MEGA 7.0 by implementing the neighbor-joining (NJ), maximum-likelihood (ML), and maximum-parsimony (MP) methods with 1000 bootstrap replicates [27]. Multilocus sequence analysis (MLSA) [28] of the partial sequences of five housekeeping genes $(r p o B, g y r B$, $\operatorname{rec} A$, fus $A$, and nifD) was performed as described by Holmes et al. [29] with the primers NIFDF2/NIFDR2, GYR48F/GYR1010R, RPO175F/RPO800R, REC300F/REC910R, and a modified primer pair for fus $A$ (Forward: 5'-CTNGACATCAAGATCTGCCC-3', Reverse: 5'-TTCGCCTCNACCTTGAACTC-3'). Subsequently, the nucleic acid sequences were translated to amino acid sequences according to the standard codons. Phylogenetic analysis of these deduced amino acid sequences was performed using the MEGA 7.0 [27] by implementing the ML method based upon the best-fit substitution model after alignment and concatenation of these five housekeeping genes.

\subsection{Genome Sequencing, Assembly and Annotation}

Genomic DNA was extracted and purified using DNeasy blood and tissue kit (Qiagen, Hilden, Germany) in accordance with the manufacturer's instructions. The draft genome sequencing of the three strains was performed using the Illumina HiSeq instrument according to the manufacturer's instructions (Illumina, San Diego, CA, USA) for $2 \times 150$ paired-end (PE) configuration at Genewiz Inc. (Suzhou, China). The resulting sequence reads were quality tested and then assembled using the Velvet (version: 1.2.10, available online: https://www.ebi.ac.uk/ \{\}zerbino/velvet/) [30]. The gaps were filled using SSPACE [31] and GapFiller [32]. Assembled contigs were used for G $+C$ content calculation and preliminary gene annotation by RAST [33] and NCBI. Translated amino acids were further assigned to KEGG pathways with the BlastKOALA server [34] and the eggNOG database using eggNOG-mapper 2 [35]. All of the reference genomes used in this study were obtained from the NCBI database and analyzed equally with the three isolated strains. All the sequences were deposited in the GenBank database and the numbers are available in the Appendix A.

\subsection{Genome Comparison}

The average nucleotide identity (ANI) and the digital DNA-DNA hybridization (dDDH) between the three strains and other type species in the family Geobacteraceae were obtained in silico using the JspeciesWS based upon the BLAST+ [36] and the Genome-to-Genome Distance Calculator 2.1 (GGDC) with recommended BLAST+ alignment and Formula 2 [37]. The average amino acid identity (AAI) and percentage of conserved protein (POCP) were determined based upon annotated protein sequences as described previously [38,39] using an online-tool (Available online: http://enve-omics.ce. gatech.edu/) and a Python script (Available online: https://github.com/2015qyliang/POCP), respectively. Phylogenetic tree based on the whole genome sequences was constructed using an up-to-date bacterial core gene (UBCG) pipeline (Available online: https://www.ezbiocloud.net/tools/ubcg) with the default parameters as described by $\mathrm{Na}$ et al. [40]. A visual genomic comparison at the nucleotide level of the three isolated strains and their relatives was carried out by the BLAST ring image generator (BRIG) with default parameters [41]. To display the locally collinear blocks (LCBs) and their similarities, the final alignments of the three strains were performed by Mauve [42] using default parameters, and then a diagrammatic representation of these alignments was generated using genoPlotR [43]. Analysis of the core genome of the three isolated was performed using the Roary (version: 3.6.0, available online: https://github.com/sanger-pathogens/Roary) [44] along with the rapid genome annotation pipeline 
Prokka (version: 1.11, available online: https://github.com/tseemann/prokka) [45]. Both of them were run with default parameters.

\subsection{Genomic Fingerprints}

For the specific fingerprints, total genomic DNA of the three isolates was used as a template for PCR amplification by the methods of random amplified polymorphic DNA (RAPD) (primer: AGCAGCGTGG) [46] and repetitive sequence-based PCR (rep-PCR) with ERIC primers (ERIC1/ERIC2) and BOX primer (BoxA1R) [47]. Then $20 \mathrm{uL}$ of the PCR products were electrophoresed in a 1.5\% agarose gel using $1 \times$ TAE buffer mixed with $3.0 \mu \mathrm{L}$ of ethidium bromide/mL under $100 \mathrm{~V}$ for $45 \mathrm{~min}$.

\subsection{Chemotaxonomic Characterization}

Fatty acid detection was performed using the cells grown in modified R2A broth which were incubated at $30^{\circ} \mathrm{C}$. The strains $\operatorname{Red} 96^{\mathrm{T}}, \operatorname{Red} 100^{\mathrm{T}}$, and $\operatorname{Red} 88^{\mathrm{T}}$ were cultured for 2 days, while the reference strain G. chapellei DSM $13688^{\mathrm{T}}$ was cultured for 4 days due to the different culture time to their late exponential growth phases. Fatty acids were extracted and methylated in accordance with the protocol described by Kuykendall et al. [48]. Subsequently, the fatty acid compositions were monitored using a gas chromatography mass spectrum (GCMS-QP2010 ultra, Shimadzu, Kyoto, Japan) with the different known fatty acids as the standard [49]. Quinones were extracted from fresh biomass grown in modified R2A broth for 5 days and purified as described previously [50]. Quinone profiles were determined by high-performance liquid chromatography (HPLC) with ACQUITY UPLC H-Class system (Waters, Milford, MA, USA) by TechnoSuruga Laboratory (Shizuoka, Japan).

\section{Results and Discussion}

\subsection{Morphological and Physiological Analysis}

The three identified strains, namely Red $96^{\mathrm{T}}$, Red100 ${ }^{\mathrm{T}}$, and Red $88^{\mathrm{T}}$, were Gram-negative, strictly anaerobic, rod-shaped, and slightly curved in appearance (Figure 1). Cells were $0.4-0.8 \mu \mathrm{m}$ wide, 1.0-3.0 $\mu \mathrm{m}$ long, and motile due to the presence of peritrichous flagella (Figure 1). The colonies grown on modified R2A plates after 5 days of incubation were red-pigmented, circular, smooth, and less than $1.5 \mathrm{~mm}$ in diameter (Figure 1). The three strains also showed a common growth condition such temperature ranging from $16-40^{\circ} \mathrm{C}$ (optimum $30-33^{\circ} \mathrm{C}$ ), $\mathrm{pH}$ ranging from $5.0-7.5$, and an optimal $\mathrm{NaCl}$ concentration of $0 \%-0.1 \%$. Additionally, the optimal $\mathrm{pH}$ for strains $\operatorname{Red} 96^{\mathrm{T}}$ and $\operatorname{Red} 88^{\mathrm{T}}$ was 5.5-6.5, and 6.0-7.0 for strain Red $100^{\mathrm{T}}$ indicating the three strains to be slightly acidophilic. Nitrate reduction occurred for strain Red $88^{\mathrm{T}}$ with ammonium production, however, no such activity was observed for the strains Red $96^{\mathrm{T}}$ and Red $100^{\mathrm{T}}$. The dithionite-reduced minus air-oxidized difference spectrum of all analyzed strains had peaks of $c$-type cytochromes. The absorption peaks for strain R $88^{\mathrm{T}}$ were 418,522 , and $552 \mathrm{~nm}$, strains $\operatorname{Red} 6^{\mathrm{T}}$ and $\operatorname{Red} 100^{\mathrm{T}}$ were 424,524 , and $554 \mathrm{~nm}$, while the reference strain G. chapellei DSM $13688^{\mathrm{T}}$ were 423,526 , and $553 \mathrm{~nm}$ (Figure S2). The spectra obtained for Red $88^{\mathrm{T}}$ were the same as that of G. metallireducens GS- $15^{\mathrm{T}}$ with absorption peaks at $418 \mathrm{~nm}, 522 \mathrm{~nm}$, and 552 $\mathrm{nm}$ [51] and were entirely different from those obtained for Red $96^{\mathrm{T}}$ and Red $100^{\mathrm{T}}$. Based on API ZYM strips, the three isolates shared same enzymatic activities, they are positive for alkaline phosphatase, leucine arylamidase, acid phosphatase, and naphthol-AS-BI-phosphohydrolase activities, while the reference strain G. chapellei DSM $13688^{\mathrm{T}}$ was positive for esterase (C4), acid phosphatase, esterase lipase (C8), and naphthol-AS-BI-phosphohydrolase activities. The three isolates had ferric-reducing ability similar to other species belonging to the family Geobacteraceae. Although the ferric reducing rate of three isolates with two different ferric types were broad, most ferric irons were reduced to ferrous irons in 10 days (Figure 2). More detailed phenotypic features of these three novel strains were described in Table 1 and the species description. 
A. Strain Red96
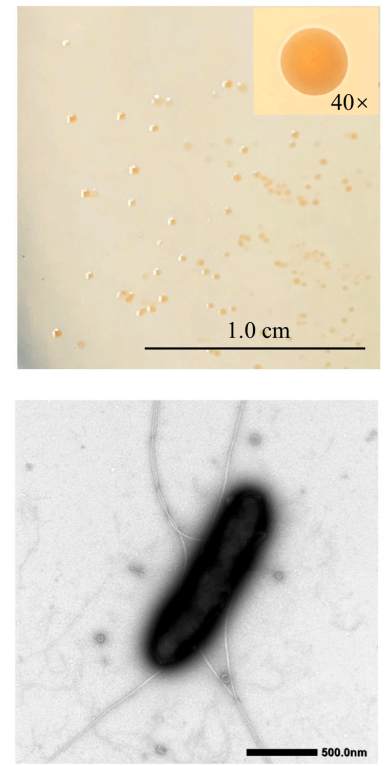

B. Strain $\operatorname{Red} 100^{\mathrm{T}}$
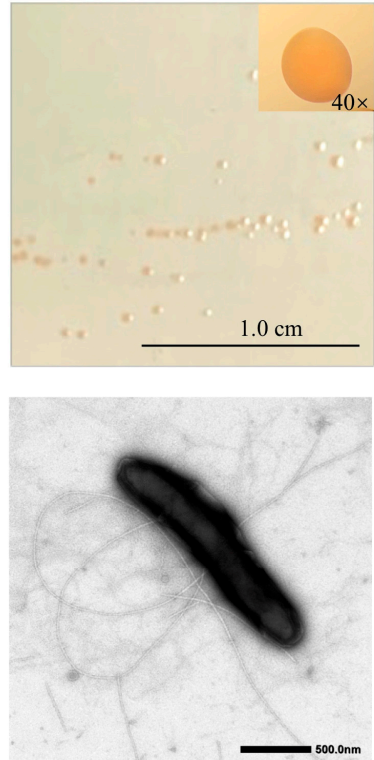

C. Strain $\operatorname{Red} 88^{\mathrm{T}}$
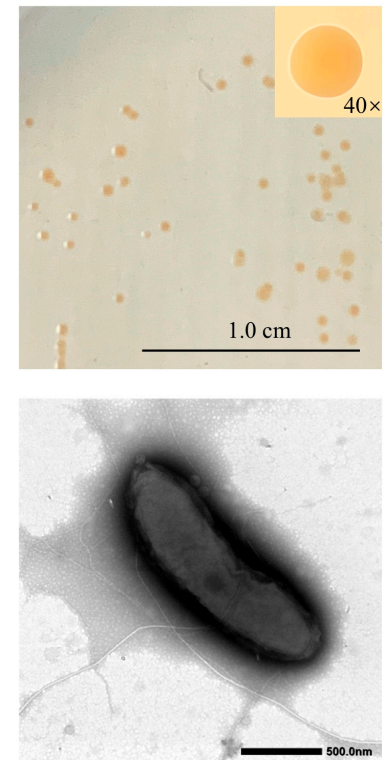

Figure 1. Colony and cell morphology of three isolated strains: Oryzomonas japonicum $\operatorname{Red} 6^{\mathrm{T}}$ (A), O. sagensis Red $100^{\mathrm{T}}(\mathbf{B})$, and O. ruber $\mathrm{R}^{\mathrm{T}} 8^{\mathrm{T}}(\mathbf{C})$. Upper and bottom panels indicate colonies on the modified R2A plate and TEM image of the cells, respectively.
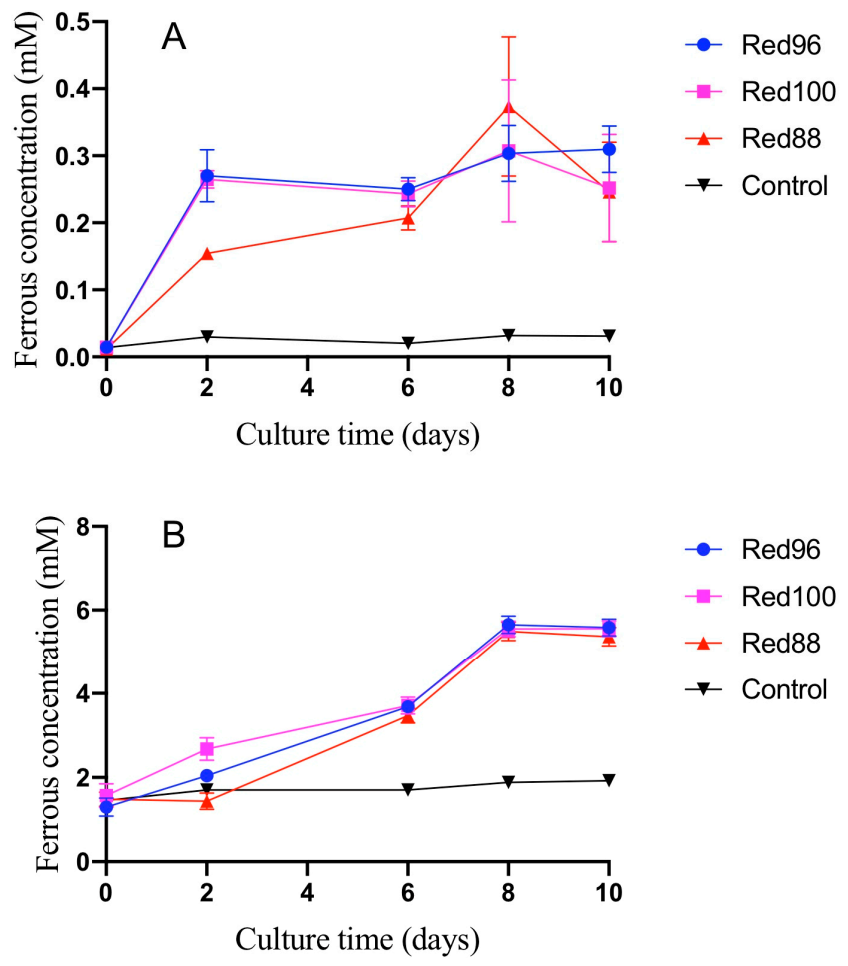

Figure 2. Reduction of insoluble Fe(III) by the three novel strains: Oryzomonas japonicum $\operatorname{Red} 6^{\mathrm{T}}$, O. sagensis Red $100^{\mathrm{T}}$, and O. ruber $\mathrm{R} 88^{\mathrm{T}}$. The experiments were performed using MFW medium with $10 \mathrm{mM}$ acetate as the electron donor. (A) Soluble ferrous concentration from Fe(III)-NTA reduction; (B) soluble ferrous concentration from Fe(III) citrate reduction. Data derived from triplicate tests were presented as means \pm standard deviations $(\mathrm{SD})$. 
Table 1. Differential characteristics between the three novel species and the type strains of phylogenetically related species of the family Geobacteraceae.

\begin{tabular}{|c|c|c|c|c|c|c|c|c|c|}
\hline Characteristic. & 1 & 2 & 3 & 4 & 5 & 6 & 7 & 8 & 9 \\
\hline Optimal temperature $\left({ }^{\circ} \mathrm{C}\right)$ & $30-33$ & $30-33$ & $30-33$ & 25 & 33 & 35 & 30 & $30-35$ & $30-33$ \\
\hline Optimal pH & $5.5-6.5$ & $6.0-7.0$ & $5.5-6.5$ & $6.5-7.0$ & $7.0-8.0$ & 6.8 & 7.0 & ca. 6.7 & $6.0-7.0$ \\
\hline $\mathrm{G}+\mathrm{C}$ content $(\mathrm{mol} \%) *$ & 59.0 & 59.7 & 58.4 & $50.2^{\mathrm{a}}$ & 58.5 & 54.8 & 52.8 & 56.6 & 61.2 \\
\hline Motility & + & + & + & - & - & + & - & - & + \\
\hline \multicolumn{10}{|l|}{ Electron acceptor usage } \\
\hline Nitrate & - & - & + & - & - & + & + & + & + \\
\hline Fumarate & + & + & + & + & - & + & + & - & + \\
\hline Sulfur & - & - & - & - & - & + & + & - & - \\
\hline $\mathrm{MnO}_{2}$ & + & - & + & + & ND & + & - & + & - \\
\hline $\begin{array}{c}\mathrm{Fe}(\mathrm{III}) \text { citrate } \\
\text { electron donor usage }\end{array}$ & + & + & + & + & ND & + & - & + & - \\
\hline Succinate & + & + & + & + & ND & - & - & - & + \\
\hline Butanol & - & - & - & - & + & ND & ND & + & - \\
\hline Ethanol & + & - & + & - & + & - & - & + & + \\
\hline Propionate & + & + & + & + & - & - & - & + & + \\
\hline Malate & + & + & + & + & - & ND & - & - & + \\
\hline Lactate & + & - & + & + & + & - & - & - & + \\
\hline Methanol & + & + & + & + & - & - & ND & - & + \\
\hline Pyruvate & + & + & + & + & + & + & - & + & + \\
\hline Glucose & + & + & + & + & - & - & ND & - & + \\
\hline Toluene & - & - & - & - & ND & - & ND & + & - \\
\hline
\end{tabular}

1. Oryzomonas japonicum $\operatorname{Red} 6^{\mathrm{T}}$ (data from this study); 2 . Oryzomonas sagensis Red $100^{\mathrm{T}}$ (data from this study); 3. Oryzomonas ruber R88 ${ }^{\mathrm{T}}$ (data from this study); 4. Geobacter chapellei DSM $13688^{\mathrm{T}}$ (data from this study); 5 . Pelobacter propionicus Ott Bd $1^{\mathrm{T}}$ (data from Schink, 1984 [52]); 6. Geobacter lovleyi SZ ${ }^{\mathrm{T}}$ (data from Sung et al., 2006 [53]); 7. Geobacter thiogenes $\mathrm{K}^{\mathrm{T}}$ (data from Nevin et al., 2007 [54]); 8. Geobacter metallireducens GS-15 ${ }^{\mathrm{T}}$ (data from Lovley et al., 1993 [3]; Zhou et al., 2014 [6]); 9. Geomonas oryzae S43 ${ }^{\mathrm{T}}$ (data from Xu et al., 2019 [2]). +, Positive; -, negative. ND, no data. ${ }^{*}$ Data from genomic analysis except: ${ }^{\text {a }}$, data from HPLC [55].

\subsection{Phylogenetic Analysis}

Phylogenetic analysis based upon the nearly complete 16S rRNA gene sequences of strains $\operatorname{Red} 6^{\mathrm{T}}$ (1428 bp, accession number MK334373), Red100 ${ }^{\mathrm{T}}$ (1429 bp, accession number MK334374), and $\operatorname{Red} 88^{\mathrm{T}}(1429 \mathrm{bp}$, accession number MK334372) demonstrated that the three strains belonged to the family Geobacteraceae in the class Deltaproteobacteria and formed a coherent branch near to Geobacter lovleyi $\mathrm{SZ}^{\mathrm{T}}$ and Geobacter thiogenes $\mathrm{K}^{\mathrm{T}}$ (Figure 3, Figures S3 and S4). On the basis of $16 \mathrm{~S}$ rRNA gene sequence similarity, the three strains were closely related to P. propionicus $\mathrm{Ott} \mathrm{Bd} 1^{\mathrm{T}}, \mathrm{G}$. lovleyi $\mathrm{SZ}^{\mathrm{T}}$, G. chapellei $172^{\mathrm{T}}$, and $\mathrm{G}$. thiogenes $\mathrm{K} 1^{\mathrm{T}}$ with similarity values ranging from $95.36 \%$ to $95.73 \%$ (Table S1). The pairwise sequence similarity was observed to be in the range of $99.37 \%$ to $99.79 \%$ for the three strains (Table S1). Phylogenetic analysis of MLSA also showed that the three isolates formed an independent group within the family Geobacteraceae (Figure 4), indicating a robust phylogenetic relationship of the three strains. 


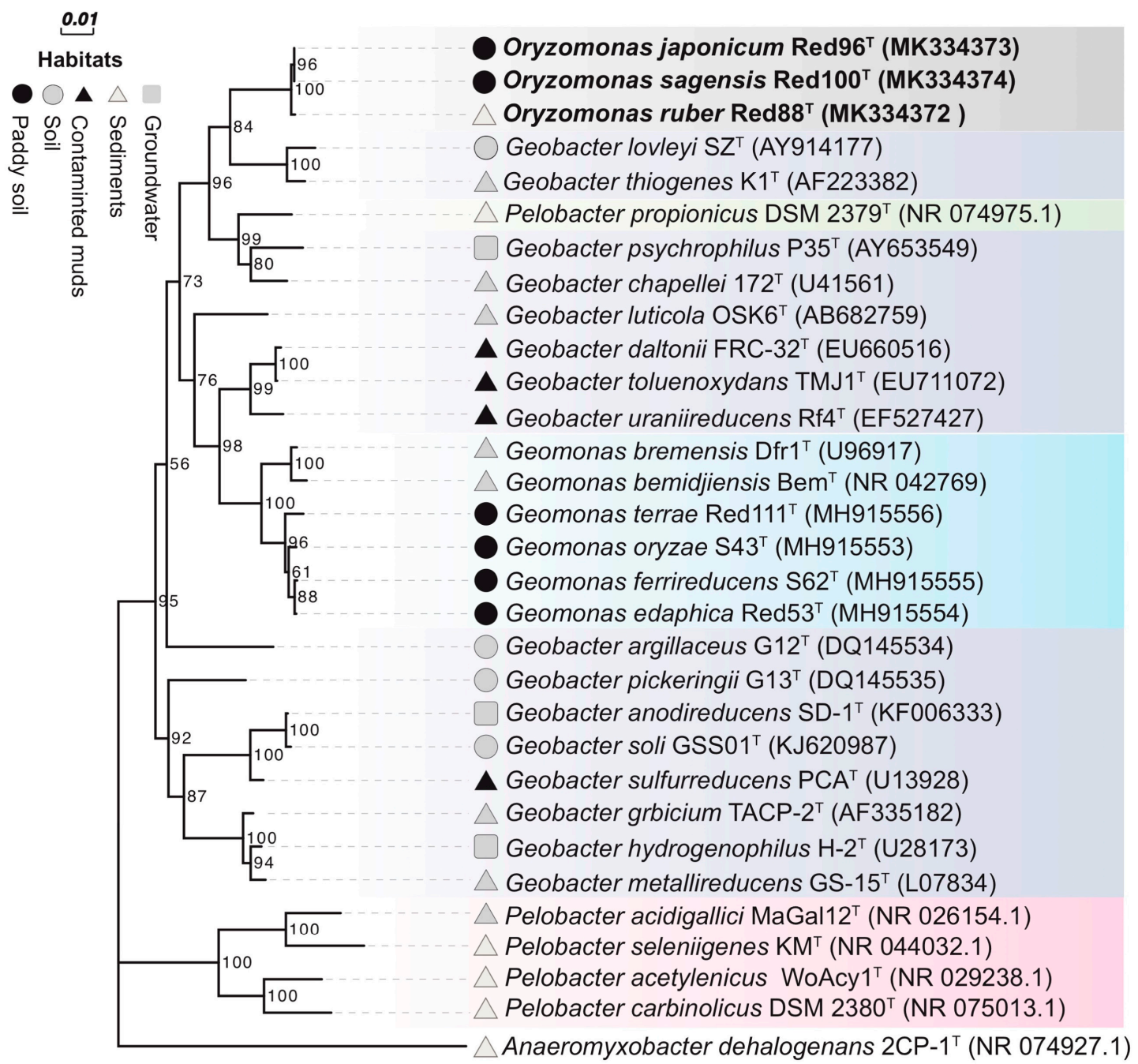

Figure 3. Phylogenetic tree of strains $\operatorname{Red} 96^{\mathrm{T}}, \operatorname{Red} 100^{\mathrm{T}}, \operatorname{Red} 88^{\mathrm{T}}$, and representatives in the order Desulfuromonadales based on 16S rRNA sequence divergence. The tree was inferred by the neighbor-joining (NJ) algorithm using MEGA 7.0 with Kimura 2-parameter model. Habitats, representing the isolation source of the type strains, are coded by different marks. The background colors represent different bacterial genera. Bootstrap values (expressed as percentages of 1000 replications) over $50 \%$ are shown at branching nodes. Bar, 0.01 substitutions per nucleotide position.

Although the three strains were considered as different taxa in the family Geobacteraceae, they showed low 16S rRNA gene similarities to the two type species, G. metallireducens GS-15 and Geomonas oryzae S43 ${ }^{\mathrm{T}}$, with values in the range of $92.22 \%-92.43 \%$, and $93.54 \%-93.75 \%$, respectively (Table S1). Moreover, Yarza et al. [56] have proposed that the generally used arbitrary genus threshold of $95 \% 16 \mathrm{~S}$ rRNA gene identity should be revised to $94.5 \%$ with a confidence interval of 94.55-95.05 and median sequence identity of $96.4 \%$. Along with the monophyletic cluster in phylogenetic trees, we hence assessed that the three strains are not the members of two proposed genera and may represent a novel genus in the family Geobacteraceae. 


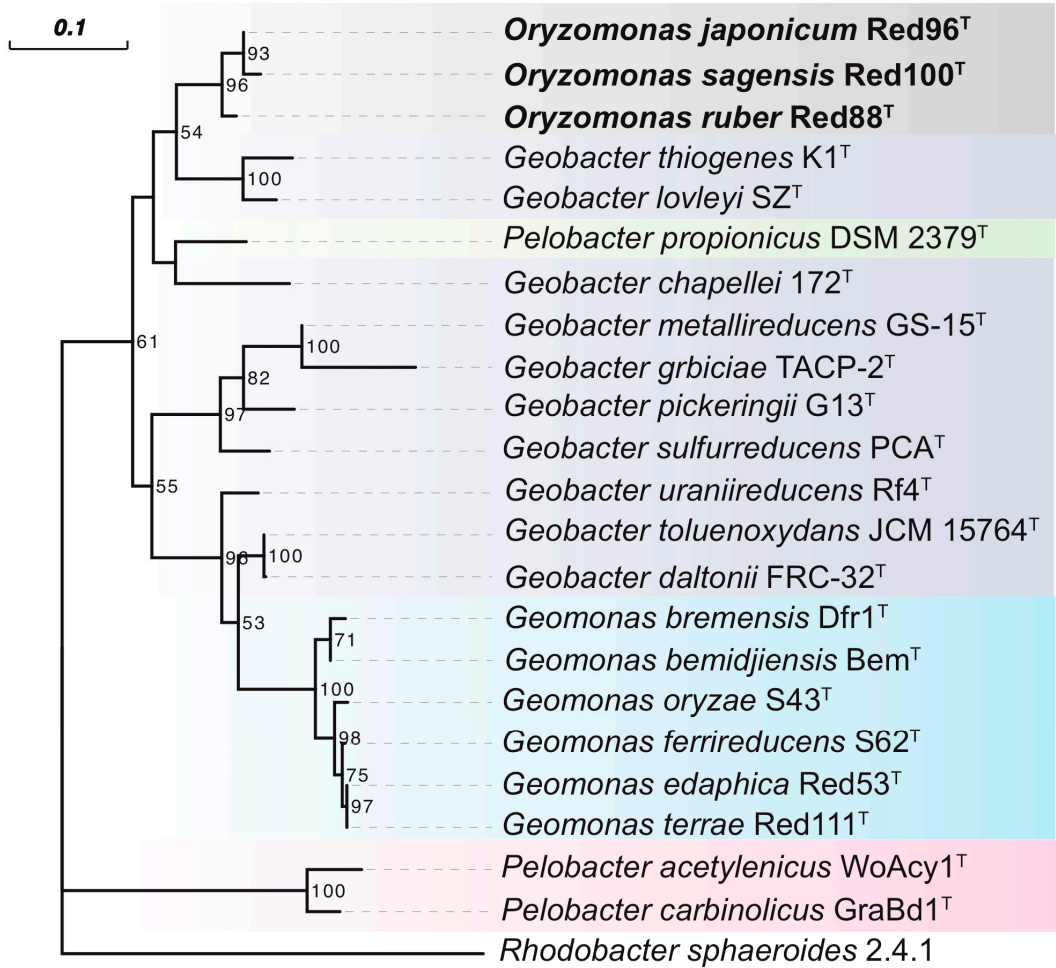

Figure 4. Phylogenetic tree of strains $\operatorname{Red} 96^{\mathrm{T}}, \operatorname{Red} 100^{\mathrm{T}}, \operatorname{Red} 88^{\mathrm{T}}$, and representatives in the order Desulfuromonadales based on deduced protein sequences of five concatenated housekeeping gene: fus $A$ (1-196 amino acids), gyrB (197-491 amino acids), nifD (492-752 amino acids), recA (753-977 amino acids) and $т р о B$ (978-1177 amino acids). The background colors represent different bacterial genera. The tree was inferred by maximum-likelihood (ML) with the best-fit substitution model (LG + G), and 1000 bootstrap replicates. Over 50\% are shown at branching nodes. Bar, 0.1 substitutions per nucleotide position.

\subsection{Genome Characteristics}

The sizes of the draft genomes of the three strains $\operatorname{Red} 96^{\mathrm{T}}, \operatorname{Red} 100^{\mathrm{T}}$, and Red $88^{\mathrm{T}}$ were 3.6, 3.6, and $3.8 \mathrm{Mb}$ contained 30, 18, and 23 contigs (>500 bp) with N50 of 336264, 620468, and $353860 \mathrm{bp}$, respectively. For strains $\operatorname{Red} 96^{\mathrm{T}}, \operatorname{Red} 100^{\mathrm{T}}$, and $\operatorname{Red} 88^{\mathrm{T}}$, a total of 3363,3322 , and 3523 potential coding sequences were predicted by RAST, respectively. Among them, 2224, 2092, and 2208 protein-coding genes were annotated and classified into different functional groups based on the SEED database (Figure S5). Besides, 3000, 2942, and 3060 genes with COG numbers were annotated using the eggNOG database (Figure S6), while 1426, 1412, and 1392 genes with ko numbers were annotated with the KEGG database (Figure S7). More detailed genomic features were listed in Table 2. The average G $+\mathrm{C}$ content of the strains Red96 ${ }^{\mathrm{T}}$, Red $100^{\mathrm{T}}$, and R88 ${ }^{\mathrm{T}}$ were $59.0,59.7$, and $58.4 \mathrm{~mol} \%$, respectively, markedly higher than those of the reference strain, G. chapellei DSM $13688^{\mathrm{T}}(50.2 \mathrm{~mol} \%)$ [55], as well as other relatives G. lovleyi $\mathrm{SZ}^{\mathrm{T}}$ ( $54.8 \mathrm{~mol} \%$ from genome) and G. thiogenes $\mathrm{K}^{\mathrm{T}}$ (52.8 $\mathrm{mol} \%$ from genome), but comparable to their another close neighbour P. propionicus Ott Bd $1^{\mathrm{T}}$ (58.5 $\mathrm{mol} \%$ from genome).

As described above, strains Red $96^{\mathrm{T}},{ }, \operatorname{Red} 100^{\mathrm{T}}$, and Red $88^{\mathrm{T}}$ exhibited the activity of Fe(III) oxide reduction (Figure 2). There are two known bacterial gene clusters involved in the ferric reduction; the porin-cytochrome genes $(p c c)$ cluster and metal-reducing gene $(m t r)$ cluster, which have originally elucidated in Geobacter sulfurreducens and Shewanella oneidensis, respectively [57]. In genomes of strains Red $96^{\mathrm{T}}$, Red $100^{\mathrm{T}}$, and Red $88^{\mathrm{T}}$, we found $p c c$ homologous including constitutive genes encoding outer membrane- $(\mathrm{OmcB} / \mathrm{C}-\mathrm{OmbB} / \mathrm{C}-\mathrm{OmaB} / \mathrm{C})$, periplasmic- $(\mathrm{PpcA})$, and cytoplasmic membrane- proteins $(\mathrm{CbcL})$ (Table S2), suggesting that these three strains reduce Fe(III) oxide by using the porin-cytochrome system as well as Geobacter spp. [58,59]. Moreover, their genomes also harbored genes involved 
in the synthesis of electrically conductive pili (e-pili), including pilA coding an e-pili assembler (Table S3, [60]). e-pili plays a key role in long-range extracellular electron transport, which allows for an electron exchange with farther minerals and microorganisms [61]. Therefore, from the viewpoint of efficient electron transfer, microorganisms having e-pili are popular research targets in the field of bioelectrochemistry and biogeochemistry, such as the development of microbial fuel cells and the bioremediation of heavy metal contaminations [62]. However, e-pili synthesis genes have been found in the genomes of limited bacterial groups [63]. Strains $\operatorname{Red} 96^{\mathrm{T}}, \operatorname{Red} 100^{\mathrm{T}}$, and $\operatorname{Red} 88^{\mathrm{T}}$ would be novel candidates as valuable microbial resources in applied biochemistry research.

Table 2. General genome features of three novel species: Oryzomonas japonicum Red96 ${ }^{\mathrm{T}}$, O. sagensis Red $100^{\mathrm{T}}$, and O. ruber $\operatorname{Red} 88^{\mathrm{T}}$.

\begin{tabular}{cccc}
\hline Features & Red96 $^{\mathbf{T}}$ & Red100 $^{\mathbf{T}}$ & Red88 $^{\mathbf{T}}$ \\
\hline Assembled contigs & 30 & 17 & 16 \\
Genome length (bp) & $3,624,587$ & $3,609,742$ & $3,798,725$ \\
N50 length (bp) & 336,264 & 620,468 & 353,860 \\
Average G + C content (mol\%) & 59.0 & 59.7 & 58.4 \\
Number of predicted ORFs & 3363 & 3322 & 3523 \\
Number of rRNAs & 5 & 4 & 3 \\
Number of tRNAs & 49 & 51 & 50 \\
Number of ncRNAs & 3 & 3 & 3 \\
Depth of coverage $(\times)$ & 808 & 958 & 271 \\
Accession number & VZQZ00000000 & VZRA01000000 & SRSD01000000 \\
\hline
\end{tabular}

\subsection{Genome Comparison}

To carry out a complete phylogenetic analysis, a phylogenetic tree based on 92 concatenated core genes (UBCG) was also constructed. This phylogenetic tree confirmed strains Red $96^{\mathrm{T}}, \operatorname{Red}_{100^{\mathrm{T}}}$, and Red $88^{\mathrm{T}}$ formed a novel robust cluster in the family Geobacteraceae (Figure 5), supporting their distinct positions with other known species. However, the phylogenetic clades in UBCG trees differed slightly in comparison to the trees which were constructed based upon the 16S rRNA sequences and MLSA (Figures 3 and 4, Figures S3 and S4). In the UBCG tree, the strain Red96 ${ }^{\mathrm{T}}$ had a closer relationship with strain Red $88^{\mathrm{T}}$ (Figure 5); however, it was observed to be closely related to the strain Red $100^{\mathrm{T}}$ based upon the 16S rRNA gene and MLSA analysis (Figures 3 and 4, Figures S3 and S4). Moreover, the discrepancy also occurred between the phylogenetically coherent branches of the three strains and their relatives for three differently constructed trees. The three isolated strains were closely related to G. lovleyi and G. thiogenes in the 16S rRNA gene and MLSA trees (Figures 3 and 4, Figures S3 and S4) as compared to that of the UBCG tree where P. propionicus was observed to the closest relative (Figure 5). These conflicting results indicate that strains $\operatorname{Red} 96^{\mathrm{T}}, \operatorname{Red} 100^{\mathrm{T}}$, and $\operatorname{Red} 88^{\mathrm{T}}$ may represent a separated taxon, including three independent subtaxa in the family Geobacteraceae.

The ANI and GGDC values were below $74.0 \%$ and $22.2 \%$, respectively, between the strains $R 88^{\mathrm{T}}$, Red $96^{\mathrm{T}}$, and Red $100^{\mathrm{T}}$ and other Geobacteraceae species (Table 3). According to the recommended species cut-off values for the ANI and GGDC (95\%-96\% and 70\%, respectively) [64], the three isolates were suggested to be a novel taxon in the family Geobacteraceae. Furthermore, the ANI and GGDC values ranged from $94.2 \%-95.6 \%$ and $58.2 \%-67.5 \%$, respectively, between each pair of the three isolates (Table 3). Among them, strain Red $100^{\mathrm{T}}$ could be clearly separated as a novel species from Red $96^{\mathrm{T}}$ and Red $88^{\mathrm{T}}$, owing to the lower ANI and GGDC values than the recommended threshold, as described above. However, slightly more variability was observed for the strains $\operatorname{Red} 88^{\mathrm{T}}$ and $\operatorname{Red} 96^{\mathrm{T}}$ because the genomic relatedness between them was $95.6 \%$ for ANI and $67.5 \%$ for GGDC (Table. 3), which were in the transition zone for proposing novel species: $95 \%-96 \%$ for ANI and $60 \%-70 \%$ for GGDC [65].

The maximum values of AAI and POCP were observed to be $66.6 \%$ and $61.6 \%$, respectively, between the three isolated strains and other Geobacteraceae species (Table 3). These values were below the threshold to separate recently-proposed genus Geomonas from other Geobacteraceae species: ca. 70\% 
for AAI and ca. 65\% for POCP (Figure 6 [2]). Previous reports indicated that the AAI and POCP, based on the amino acid sequences comparison, are robust approaches to determine the bacterial genera separation $[39,66]$. Together with the above $16 \mathrm{~S}$ rRNA gene similarities and phylogenetic analysis, we concluded that the three analyzed strains represent a novel genus in the family Geobacteraceae.

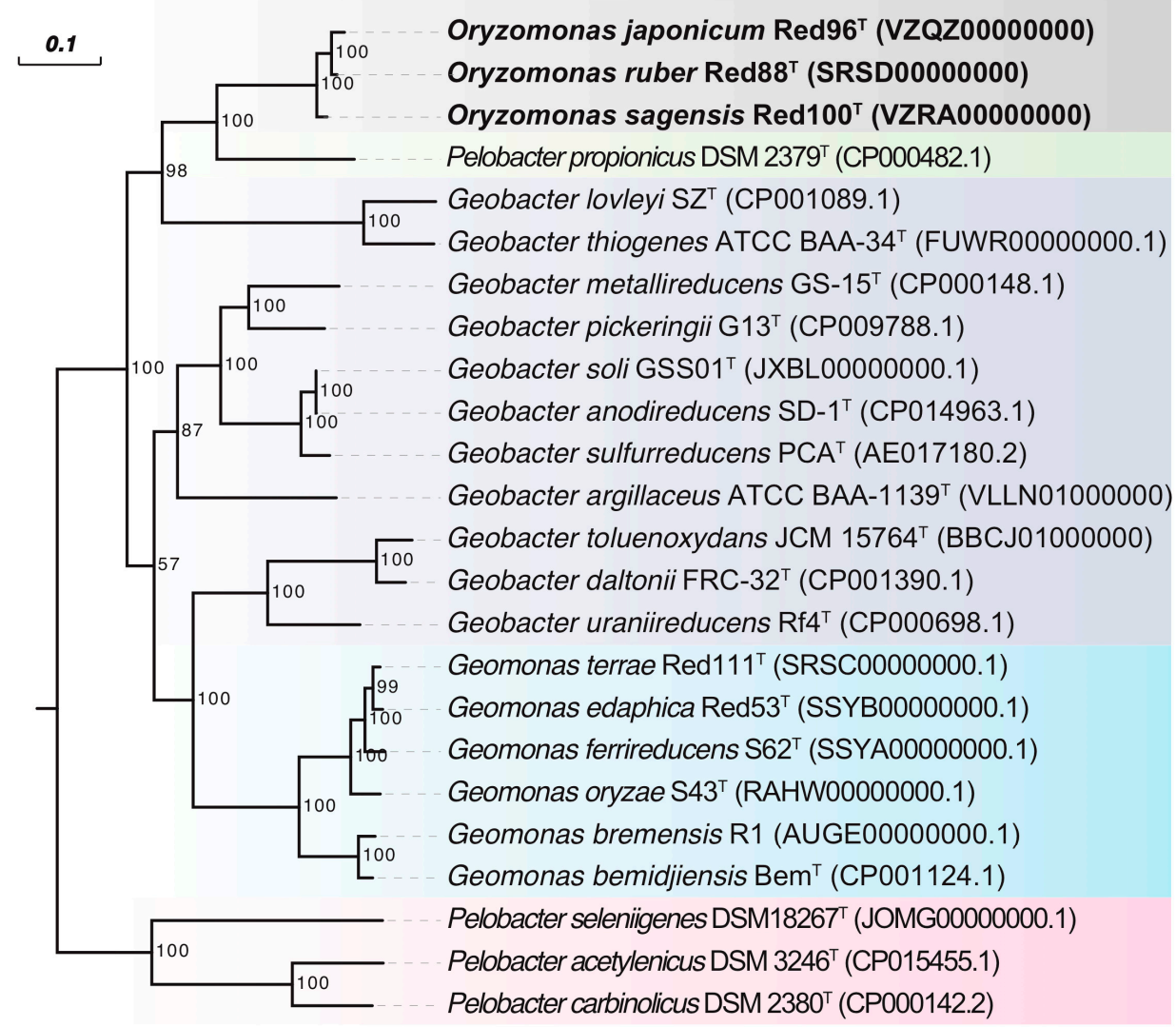

Figure 5. Phylogenetic tree of strains $\operatorname{Red} 96^{\mathrm{T}}, \operatorname{Red} 100^{\mathrm{T}}, \operatorname{Red} 88^{\mathrm{T}}$, and representatives in the order Desulfuromonadales based on the whole genome sequences. The tree was reconstructed based on a concatenated alignment of 92 core genes using RAxML tool with GTR + CAT model [40]. The background colors represent different bacterial genera. Bootstrap values (expressed as percentages of 100 replications) over $50 \%$ are shown at branching nodes. Bar, 0.1 substitutions per nucleotide position.

Additionally, the BRIG analysis suggested that most genomic regions of the five analyzed strains were conserved with at least 70\% identity (Figure 7). Moreover, strains $\operatorname{Red} 96^{\mathrm{T}}, \operatorname{Red}_{100^{\mathrm{T}}}$, and $\operatorname{Red} 88^{\mathrm{T}}$ showed higher identity with each other compared with the two reference strains in most genomic regions, implying that the three isolated strains are much closer to each other than to G. lovleyi and $P$. propionicus. Based on the core genomes, most genes (ca. 60\%) were found shared by the three strains, and the less (ca. 20\%) were unique genes (Figure 8), showing the comparability and individuality among them. Detailed analysis also revealed that strain Red $96^{\mathrm{T}}$ shared more genes with strain $\operatorname{Red} 88^{\mathrm{T}}$ (412), but less with strain $\operatorname{Red}_{100^{\mathrm{T}}}$ (93), indicating strain $\operatorname{Red}^{\mathrm{T}} 6^{\mathrm{T}}$ had a closer relationship with strain Red $88^{\mathrm{T}}$, which is consistent with genomic phylogenetic analysis, but dissimilar with the guide tree of Mauve alignment (Figure 9), which showed strains $\operatorname{Red}^{2} 6^{\mathrm{T}}$ and $\operatorname{Red}_{100^{\mathrm{T}}}$ are more closely related to each other than to strain $\operatorname{Red} 88^{\mathrm{T}}$. Besides that, the Mauve alignment also displayed the presence of all LCBs with partial regions of inversion and rearrangement, as well as a strong synteny among these three strains (Figure 9). Although the guide tree of Mauve alignment is distinct from genomic analysis (Figures 5 and 9; Table 3), it agrees with the phylogenetic analysis of MLSA and 16S rRNA (Figures 3 and 4, Figures S3 and S4). This conflicting result further proved the individual status of these three strains. 
Table 3. Genomic similarities (\%) of ANI, GGDC, AAI, and POCP between the three strains and other type species in the family Geobacteraceae.

\begin{tabular}{|c|c|c|c|c|c|c|c|c|c|c|c|c|}
\hline \multirow{2}{*}{ Reference Strains \# } & \multicolumn{3}{|c|}{ ANI Value (\%) } & \multicolumn{3}{|c|}{ GGDC Value (\%) } & \multicolumn{3}{|c|}{ AAI Value (\%) } & \multicolumn{3}{|c|}{ POCP (\%) } \\
\hline & ${\operatorname{Red} 96^{T}}^{T}$ & $\operatorname{Red} 100^{\mathrm{T}}$ & ${\text { Red } 88^{T}}^{T}$ & ${\operatorname{Red} 96^{T}}^{\mathrm{T}}$ & $\operatorname{Red} 100^{\mathrm{T}}$ & $\operatorname{Red} 88^{T}$ & ${\operatorname{Red} 96^{\mathrm{T}}}^{2}$ & $\operatorname{Red} 100^{T}$ & $\operatorname{Red} 88^{\mathrm{T}}$ & $\operatorname{Red96}{ }^{\mathrm{T}}$ & $\operatorname{Red}_{100}{ }^{\mathrm{T}}$ & $\operatorname{Red}^{2} 8^{\mathrm{T}}$ \\
\hline Oryzomonas japonicum Red96 $^{\mathrm{T}}$ & 100 & & & 100 & & & 100 & & & 100 & & \\
\hline Oryzomonas sagensis Red $100^{\mathrm{T}}$ & 94.2 & 100 & & 58.2 & 100 & & 95.0 & 100 & & 86.0 & 100 & \\
\hline Oryzomonas ruber $\operatorname{Red} 88^{\mathrm{T}}$ & 95.6 & 94.6 & 100 & 67.5 & 61.7 & 100 & 96.3 & 95.2 & 100 & 85.0 & 83.5 & 100 \\
\hline Pelobacter propionicus $\mathrm{Ott} \mathrm{Bd} 1^{\mathrm{T}}$ & 73.8 & 74.0 & 73.9 & 20.6 & 21.1 & 21.1 & 66.6 & 66.6 & 66.4 & 52.6 & 51.8 & 50.8 \\
\hline Geobacter lovleyi $\mathrm{SZ}^{\mathrm{T}}$ & 70.7 & 70.6 & 70.8 & 19.8 & 19.9 & 19.8 & 63.6 & 63.6 & 63.4 & 56.3 & 55.4 & 54.8 \\
\hline Geobacter thiogenes ATCC BAA- $34^{\mathrm{T}}$ & 70.3 & 70.0 & 70.3 & 19.2 & 20.0 & 19.7 & 63.7 & 63.5 & 63.2 & 55.8 & 54.7 & 53.6 \\
\hline Geobacter metallireducens GS-15 $15^{\mathrm{T}}$ & 70.8 & 70.9 & 70.8 & 20.2 & 19.9 & 20.2 & 62.3 & 62.4 & 62 & 57.8 & 57.3 & 56.6 \\
\hline Geobacter uraniireducens Rf4 ${ }^{\mathrm{T}}$ & 70.7 & 70.6 & 70.4 & 20.2 & 20.6 & 20.3 & 62.8 & 62.1 & 62.3 & 54.3 & 53.7 & 53.0 \\
\hline Geobacter toluenoxydans JCM $15764^{\mathrm{T}}$ & 69.7 & 69.8 & 69.5 & 20.0 & 20.5 & 19.3 & 61.1 & 60.8 & 60.5 & 49.4 & 49.0 & 47.8 \\
\hline Geobacter daltonii $\mathrm{FRC}-32^{\mathrm{T}}$ & 69.6 & 69.5 & 69.3 & 20.3 & 22.2 & 20.6 & 61.3 & 61.0 & 60.7 & 54.9 & 54.5 & 53.1 \\
\hline Geobacter sulfurreducens $\mathrm{PCA}^{\mathrm{T}}$ & 70.8 & 70.8 & 70.9 & 20.0 & 20.5 & 20.2 & 62.6 & 62.7 & 62.3 & 60.3 & 59.7 & 59.0 \\
\hline Geobacter anodireducens SD-1 ${ }^{\mathrm{T}}$ & 71.0 & 71.0 & 71.1 & 19.7 & 20.2 & 20.0 & 61.4 & 61.4 & 61.3 & 53.5 & 53.2 & 52.5 \\
\hline Geobacter pickeringii $\mathrm{G}^{3} 3^{\mathrm{T}}$ & 71.5 & 71.4 & 71.5 & 20.3 & 20.7 & 20.6 & 63.3 & 63.3 & 63.4 & 61.6 & 61.6 & 60.4 \\
\hline Geobacter soli GSS01 ${ }^{\mathrm{T}}$ & 71.0 & 71.0 & 71.0 & 19.8 & 20.3 & 20.1 & 62.4 & 62.3 & 62.3 & 59.4 & 58.9 & 58.4 \\
\hline Geomonas oryzae $\mathrm{S} 43^{\mathrm{T}}$ & 70.3 & 70.5 & 70.3 & 19.3 & 19.4 & 19.3 & 60.8 & 60.7 & 60.7 & 57.8 & 56.9 & 56.9 \\
\hline Geomonas edaphica Red53 ${ }^{\mathrm{T}}$ & 70.3 & 70.3 & 70.2 & 19.2 & 19.1 & 19.3 & 60.9 & 60.9 & 60.6 & 58.0 & 56.7 & 56.8 \\
\hline Geomonas ferrireducens $\mathrm{S} 62^{\mathrm{T}}$ & 70.3 & 70.3 & 70.3 & 19.3 & 19.2 & 19.5 & 60.9 & 60.6 & 60.5 & 57.4 & 56.0 & 55.8 \\
\hline Geomonas terrae Red $111^{\mathrm{T}}$ & 69.8 & 70.0 & 69.9 & 19.0 & 19.3 & 19.2 & 60.5 & 60.6 & 60.3 & 58.1 & 56.6 & 56.7 \\
\hline Geomonas bemidjiensis $\mathrm{Bem}^{\mathrm{T}}$ & 70.2 & 70.3 & 70.2 & 19.8 & 19.8 & 19.9 & 60.6 & 60.6 & 60.5 & 56.8 & 56.1 & 56.1 \\
\hline Geomonas bremensis R1 & 70.4 & 70.2 & 70.3 & 19.9 & 19.9 & 19.9 & 60.4 & 60.4 & 60.1 & 56.4 & 55.7 & 55.5 \\
\hline
\end{tabular}

\# Genomes of all reference strains were retrieved from the NCBI database with the accession numbers and genome size listed in Table S4. 


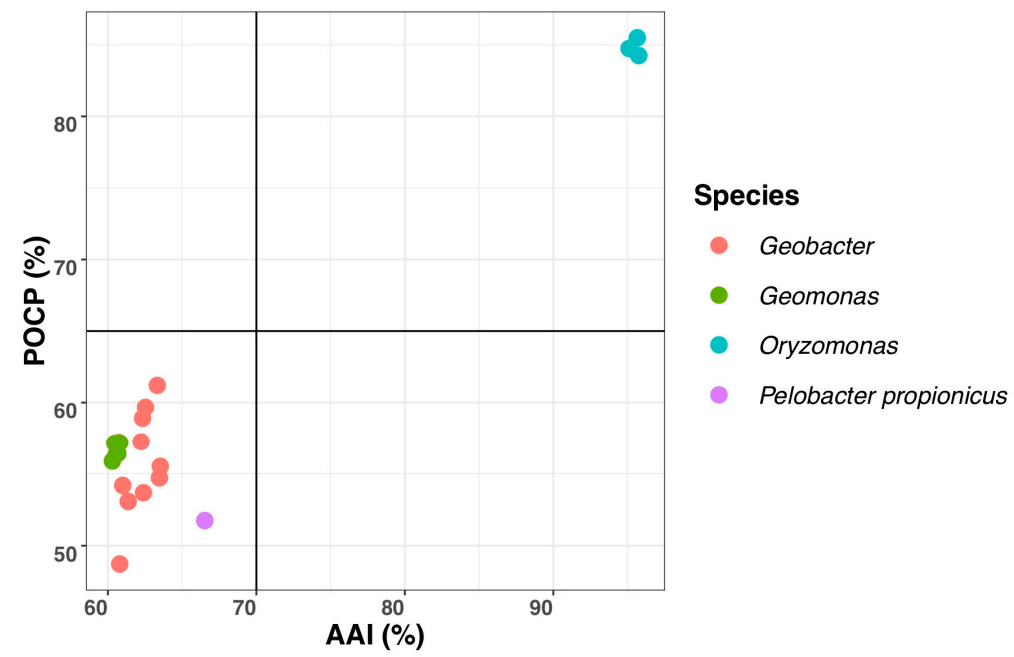

Figure 6. Comparisons of genomic similarities based on AAI and POCP values. The points represent average comparison values between the three novel strains and their close relatives in the family Geobacteraceae. A total of 20 genomes were included in this analysis.

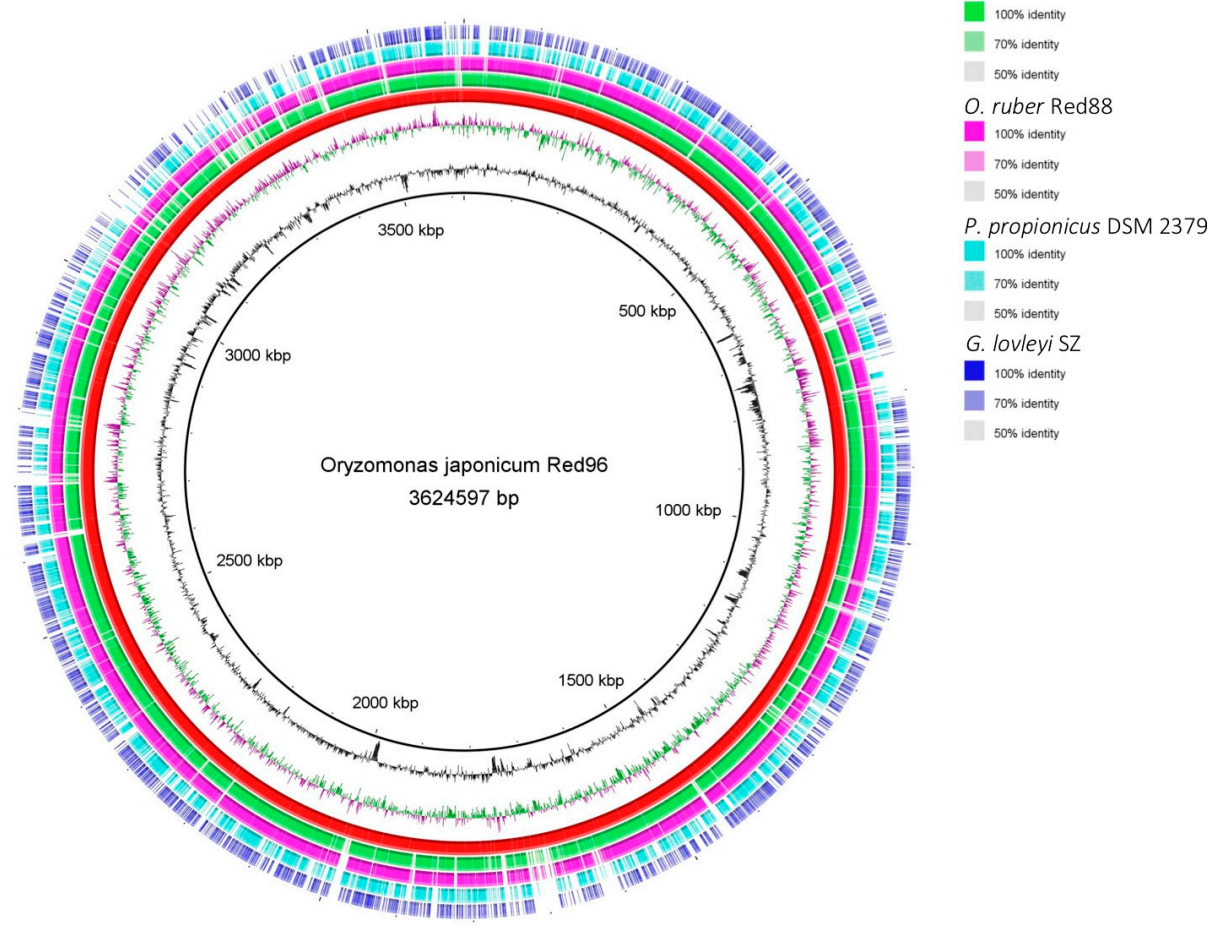

Figure 7. Circular representation of whole-genome sequences of Oryzomonas japonicum Red96 ${ }^{\mathrm{T}}, \mathrm{O}$. sagensis $\operatorname{Red} 100^{\mathrm{T}}$, O. ruber $\mathrm{R} 88^{\mathrm{T}}$, and their two neighbors: Pelobacter propionicus DSM $2379^{\mathrm{T}}$ and Geobacter lovleyi $\mathrm{SZ}^{\mathrm{T}}$. The rings from inner to outer: ring 1-GC content, ring 2-GC skew, ring 3-whole-genome sequences of O. japonicum Red $96^{\mathrm{T}}$ (red), ring 4-whole-genome sequences of O. sagensis $\operatorname{Red} 100^{\mathrm{T}}$ (green), ring 5-whole-genome sequences of $O$. ruber R88 ${ }^{\mathrm{T}}$ (pink), ring 6-whole genome sequences of $P$. propionicus DSM $2379^{\mathrm{T}}$ (cyan), ring 7-whole-genome sequences of G. lovleyi $\mathrm{SZ}^{\mathrm{T}}$ (blue). The genome of O. japonicum Red $96^{\mathrm{T}}$ was used as the reference for global comparisons. 


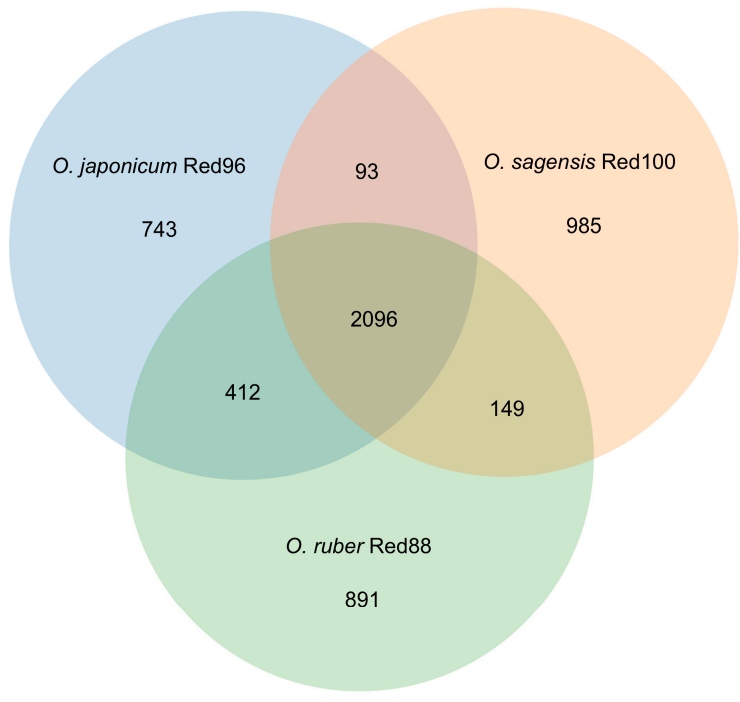

Figure 8. Venn diagram of homologs showing the number of shared coding regions among the three strains Oryzomonas japonicum Red96 ${ }^{\mathrm{T}}$ (blue), O. sagensis Red $100^{\mathrm{T}}$ (red), and O. ruber $\mathrm{R}^{2} 8^{\mathrm{T}}$ (green).

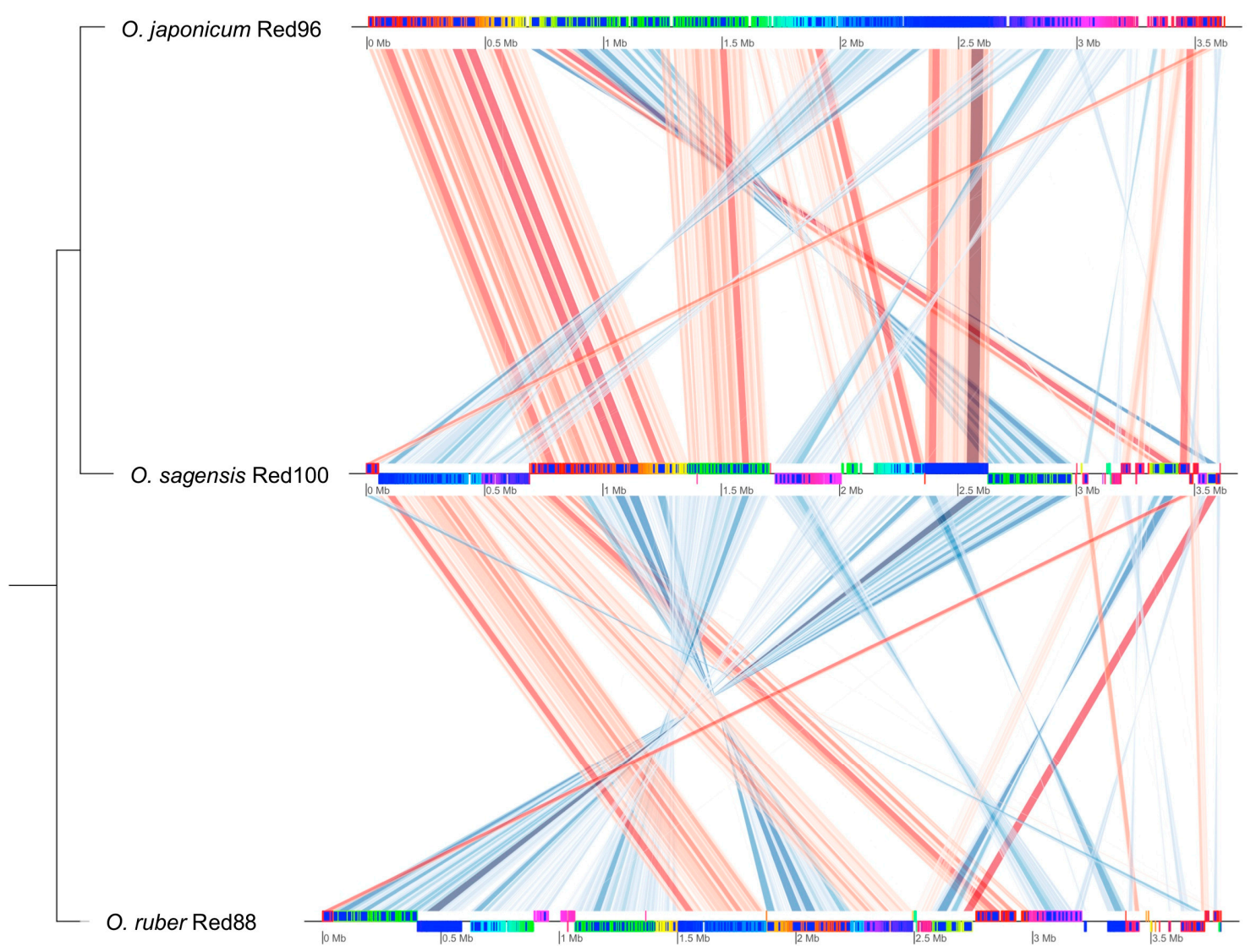

Figure 9. Multiple genome alignment of the three novel strains Oryzomonas japonicum Red96 ${ }^{\mathrm{T}}$ (top), O. sagensis Red $100^{\mathrm{T}}$ (middle), and O. ruber $\mathrm{R} 88^{\mathrm{T}}$ (bottom). The genome of O. japonicum Red $96^{\mathrm{T}}$ was used as the reference for global alignment. Lines connect the homologous local conserved blocks (LCBs) between the genomes, with red color showing the connection between LCBs that are in the same orientation and blue color showing the connection between LCBs that are in the opposite orientation. Conserved and highly related regions are deeply colored. The tree shown on the left represents the guide tree of the Mauve alignment. 


\subsection{Genomic Fingerprints}

The banding patterns obtained using rep-PCR to fingerprint the three isolates have are shown in Figure S8. The banding patterns of the three isolates were obviously different from each other, indicating that the three isolates were not of clonal origin and were clearly different from each other.

\subsection{Chemotaxonomic Characterization}

The fatty acid profiles of the three isolates and the reference strain G. chapellei DSM $13688^{\mathrm{T}}$ are shown in Table 4. Predominant fatty acids of the three isolates were identified as iso- $\mathrm{C}_{15: 0}$ and $\mathrm{C}_{16: 1} \omega 7 c$, with an aggregate proportion accounting for more than $50 \%$ of all fatty acids. Besides, the strains $\operatorname{Red} 100^{\mathrm{T}}$ and $\operatorname{Red} 88^{\mathrm{T}}$ also contained $\mathrm{C}_{16: 0}$ in greater proportions, which were $10.8 \%$ and $13.8 \%$, respectively. $C_{16: 1} \omega 7 c, C_{16: 0}$, and iso- $C_{15: 0}$ were determined as the predominant fatty acids (relative account $>10 \%$ ) for the reference strain $G$. chapellei DSM $13688^{\mathrm{T}}$ showing similar compositions to those of the three strains, however, the relative proportions distinguished them clearly. Other minor fatty acid profiles of these strains show no significant differences. The predominant respiratory quinone of the three strains was MK-8, in agreement with the major quinone component of other Geobacteraceae species $[2,5,6]$.

Table 4. Fatty acid compositions of the three novel strains and the reference strain Geobacter chapellei DSM $13688^{\mathrm{T}}$.

\begin{tabular}{ccccc}
\hline Fatty Acid & $\mathbf{1}$ & $\mathbf{2}$ & $\mathbf{3}$ & $\mathbf{4}$ \\
\hline $\mathrm{C}_{12: 0}$ & - & - & 0.1 & 1.9 \\
iso-C $_{13: 0}$ & 0.2 & 0.3 & 0.3 & 2.6 \\
$\mathrm{C}_{14: 0}$ & 5.5 & 9.4 & 9.9 & 4.5 \\
iso-C $_{15: 0}$ & 52.1 & 40.4 & 33.5 & 19.1 \\
a-C $_{15: 0}$ & 0.7 & 0.5 & 0.5 & 0.8 \\
$\mathrm{C}_{15: 0}$ & 0.4 & 0.6 & 0.4 & 0.4 \\
$\mathrm{C}_{15: 1} \mathrm{~B} / \mathrm{F}^{*}$ & 1.4 & 1.3 & 1.3 & 0.4 \\
iso-C $_{16: 0}$ & 1.7 & 0.8 & 0.8 & 1.3 \\
$\mathrm{C}_{16: 0}$ & 7.4 & 10.8 & 13.8 & 20.1 \\
$\mathrm{C}_{16: 1} \mathrm{~B} / \mathrm{F}^{*}$ & 1.9 & 0.5 & 0.4 & 1.9 \\
$\mathrm{C}_{16: 1} \omega 7 \mathrm{c}$ & 19.2 & 22.2 & 26.0 & 32.9 \\
$\mathrm{C}_{16: 1} \omega 5 \mathrm{c}$ & 0.7 & 0.6 & 1.0 & 2.1 \\
$\mathrm{C}_{16: 0} 10-\mathrm{methyl}$ & 0.9 & 0.6 & 0.8 & $\mathrm{ND}$ \\
$\mathrm{C}_{16: 0} 3-\mathrm{OH}$ & 2.2 & 7.0 & 7.4 & 7.3 \\
$\mathrm{C}_{17: 1} \mathrm{~B} / \mathrm{F}^{*}$ & 1.6 & 0.6 & 0.5 & 0.3 \\
iso- $_{17: 0}$ & 1.5 & 0.9 & 0.8 & 0.9 \\
$\mathrm{a}-\mathrm{C}_{17: 0}$ & 0.1 & 0.1 & 0.1 & 0.2 \\
$\mathrm{C}_{18: 0}$ & 0.3 & 0.6 & 0.6 & 1.1 \\
$\mathrm{C}_{18: 1} \omega 7 \mathrm{c}$ & 1.5 & 1.1 & 1.0 & 0.4 \\
\hline
\end{tabular}

1. Oryzomonas japonicum Red $96^{\mathrm{T}} ; 2$. Oryzomonas sagensis $\operatorname{Red} 100^{\mathrm{T}} ; 3$. Oryzomonas ruber $\mathrm{R} 88^{\mathrm{T}}$; 4 . Geobacter chapellei DSM $13688^{\mathrm{T}}$. All data listed in this table derived from this study, only those accounting for $0.2 \%$ or more of the total in one or more of the strains are given. -, trace quantities $(<0.1 \%)$. ND, not detected. * The double bond position could not be identified (except for $\mathrm{C}_{15: 1} \omega 5 \mathrm{c}, \mathrm{C}_{16: 1} \omega 5 \mathrm{c}, \mathrm{C}_{16: 1} \omega 7 \mathrm{c}$, and $\mathrm{C}_{17: 1} \omega 7 \mathrm{c}$ ).

\section{Conclusions}

In this study, three Geobacter-related strains, namely $\operatorname{Red} 96^{\mathrm{T}}$, $\operatorname{Red} 100^{\mathrm{T}}$, and $\operatorname{Red} 88^{\mathrm{T}}$, were isolated from the paddy soils and pond sediment in Japan. Taxonomic and phylogenetic analysis of the nearly complete 16S rRNA gene sequences and five concatenated housekeeping genes revealed that the three isolated strains were most similar to the species in the family Geobacteraceae, however, they shared lower 16S rRNA similarities with the two type species, G. metallireducens GS-15 ${ }^{\mathrm{T}}$ and G. oryzae S43 ${ }^{\mathrm{T}}$. Moreover, the three strains showed a remarkable physiological difference from their close neighbour P. propionicus Ott Bd $1^{\mathrm{T}}$, because P. propionicus can neither utilize acetate as an electron donor nor oxidizes organic compounds completely [52]. Additionally, unlike the three isolated strains, P. propionicus did not 
contain the $c$-type cytochromes that are involved in electron transfer to Fe(III) [52]. Meanwhile, these three strains also differed from the other two neighbors, Geobacter lovleyi $\mathrm{SZ}{ }^{\mathrm{T}}$ and Geobacter thiogenes $\mathrm{K} 1^{\mathrm{T}}$, because both of them were tested in this study that they cannot grow using R2A agar plates or broth with $5 \mathrm{mM}$ fumarate. Genomic analysis based on the ANI and GGDC values indicated the three strains represented at least two novel species $\left(\operatorname{Red} 96^{\mathrm{T}}\right.$ and $\left.\operatorname{Red} 100^{\mathrm{T}}\right)$ with the values below the threshold for species separation, though the status of Red $88^{\mathrm{T}}$ could not be determined. Furthermore, the AAI and POCP showed lower values between the three strains and their relatives than the delineation proposed for genera separation in the family Geobacteraceae. These facts suggest that the three strains represent a novel genus in the family Geobacteraceae.

Although the strain Red $88^{\mathrm{T}}$ could not be separated clearly from Red $96^{\mathrm{T}}$, owing to the high genomic relatedness located in the transition zone for novel species description, their biochemical and physiological characteristics, including the optimal growth conditions, absorption peaks of c-type cytochromes, alternative electron donors/acceptors, and fatty acid profiles, clearly differed. Furthermore, the inconsistent phylogenetic positions of the three strains in the three phylogenetic trees also suggests the independent statuses of the three isolated strains, as also supported by the core genome and rep-PCR analysis. Thus, based upon the phenotypic, chemotaxonomic, phylogenetic, and genomic characterizations performed in this study, we concluded that these three strains represented three novel species of a novel genus in the family Geobacteraceae. Hence, we proposed a novel genus, Oryzomonas gen. nov. sp. nov., comprising three novel species: Oryzomonas japonicum sp. nov., Oryzomonas sagensis sp. nov., and Oryzomonas ruber sp. nov.

Furthermore, functional tests revealed that these three strains have the ferric reducing ability, and the genomic analysis suggested that they have the long-range electron transportable capacity using their e-pili. As reported previously [4], such capacity enables the efficiency of electron transportation between metal compounds to improve, leading to metal-reducing microorganisms with e-pili being of a great significance in bioremediation of hazardous metals such as $\mathrm{U}$, Se, As, and Cr, and development of microbial fuel cells [4]. Hence, this study not only improves our understanding for the diversity of important environmental microorganisms but also provides novel valuable microbial resources in applied biogeochemical science.

Together with our previous study [2], 6 type species (4 Geomonas and 2 Oryzomonas) of the family Geobacteraceae were isolated from paddy soil and revealed to be phylogenetically derivative but distinct from traditional Geobacter (Figures 3-5). Although the substantial research based on culture-independent methods indicate the predominance of Geobacter in paddy soils as described above, Geomonas and Oryzomonas have been probably confined to 'Geobacter' in such previous research. In order to improve our understanding of diversity of predominant members in paddy soils, a careful phylogenetic analysis should be done, taking into account the Geomonas and Oryzomonas, in data sets obtained from previous and future culture-independent approaches.

Description of Oryzomonas gen. nov.: Oryzomonas (O.ry.zo.mo'nas. Gr. fem. n. oryza, rice; L. fem. n. monas, a unit, monad; N.L. fem. n. Oryzomonas, a monad from rice soil). Cells are strictly anaerobic, Gram-negative, and rod-shaped. Colonies on R2A agar plates supplementary with $5 \mathrm{mM}$ fumarate are smooth, spherical and red-pigmented. Able to use Fe(III) citrate, Fe(III)-NTA, ferrihydrite and fumarate as the electron acceptors along with a variety of different electron donors, including yeast powder, acetate, tryptone, succinate, glucose, pyruvate, glycerol, propionate, methanol, and malate. The predominant fatty acids are iso- $C_{15: 0}$, and $C_{16: 1} \omega 7 c$. The major quinone is $M K-8$. The type species is Oryzomonas japonicum.

Description of Oryzomonas japonicum sp. nov.: Oryzomonas japonicum (ja.po'ni.ca. N.L. fem. adj. japonica Japanese, pertaining to Japan). Displays the following properties besides those given in the genus description. Cells are rod shaped with light curve in appearance $(0.4-0.8 \mu \mathrm{m}$ wide, 1.0-3.0 $\mu \mathrm{m}$ long) and motile with peritrichous flagella. Strains display good growth on R2A agar plus 5-20 mM fumarate and freshwater medium. Growth occurs at $16-40{ }^{\circ} \mathrm{C}$ (optimum, $30-33{ }^{\circ} \mathrm{C}$ ), at $\mathrm{pH}$ 5.0-7.5 (optimum, 5.5-6.5), and with $0 \%-0.7 \%(w / v) ~ \mathrm{NaCl}$ (optimum, $0-0.1 \%$ ). Can also utilize lactate, 
mannitol, ethanol, casamino acid, nicotinate, glutamine, arginine, serine, and proline as electron donors in the presence of Fe(III)-NTA as electron acceptor, but not phenol, isopropanol, toluene, butanol, benzaldehyde or benzyl alcohol. Can also utilize Fe(III) pyrophosphate, Fe(III)-EDTA and $\mathrm{MnO}_{2}$ as electron acceptors in the presence of acetate as electron donor, but not sulfur, nitrite or nitrate. Alkaline phosphatase, acid phosphatase, leucine arylamidase, and naphthol-AS-BI-phosphohydrolase activities were present but valine arylamidase, esterase (C4), trypsin, esteraselipase (C8), lipase (C14), cystine arylamidase, $\alpha$-glucosidase, $\alpha$-chymotrypsin, $\alpha$-galactosidase, $\alpha$-mannosidase, $\beta$-galactosidase, $\beta$-glucuronidase, $\beta$-glucosidase, $\mathrm{N}$-acetyl- $\beta$-glucosaminidase, and $\alpha$-fucosidase activities are absent. The predominant fatty acids are iso- $C_{15: 0}$ and $C_{16: 1} \omega 7 c$. The type strain, $\operatorname{Red} 6^{\mathrm{T}}\left(=\mathrm{NBRC} 114286^{\mathrm{T}}=\right.$

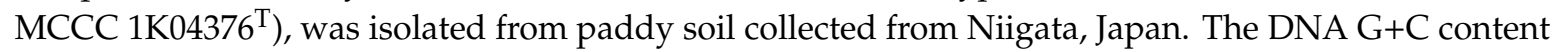
of type strain is $59.0 \mathrm{~mol} \%$.

Description of Oryzomonas sagensis sp. nov.: Oryzomonas sagensis (sa.gen'sis. N.L. fem. adj. sagensis, of or pertaining to the Saga Prefecture of Japan). Displays the following properties besides those given in the genus description. Cells are rod shaped with light curve in appearance $(0.4-0.8 \mu \mathrm{m}$ wide, 1.0-2.5 $\mu \mathrm{m}$ long) and motile with peritrichous flagella. Strains display good growth on R2A agar plus 5-20 mM fumarate and freshwater medium. Growth occurs at $16-40{ }^{\circ} \mathrm{C}$ (optimum, 30-33 ${ }^{\circ} \mathrm{C}$ ), at pH 5.0-7.5 (optimum, 6.0-7.0), and with $0 \%-0.5 \%(w / v) ~ \mathrm{NaCl}$ (optimum, $0 \%-0.1 \%$ ). Can also utilize glutamine, mannitol, nicotinate, casamino acid, arginine, serine, and proline as electron donors in the presence of Fe(III)-NTA as the electron acceptor, but not toluene, isopropanol, phenol, lactate, butanol, benzyl alcohol, ethanol, or benzaldehyde. Can also utilize Fe(III)-EDTA and Fe(III) pyrophosphate as electron acceptor in the presence of acetate as electron donor, but not sulfur, $\mathrm{MnO}_{2}$, nitrite or nitrate. Alkaline phosphatase, naphthol-AS-BI-phosphohydrolase, acid phosphatase and leucine arylamidase activities were present but esterase (C4), trypsin, lipase (C14), valine arylamidase, esteraselipase (C8), cystine arylamidase, $\alpha$-chymotrypsin, $\alpha$-glucosidase, $\alpha$-fucosidase, $\alpha$-galactosidase, $\alpha$-mannosidase, $\beta$-galactosidase, $\beta$-glucosidase, $\beta$-glucuronidase, and $\mathrm{N}$-acetyl- $\beta$-glucosaminidase activities are absent. The predominant fatty acids are iso- $C_{15: 0}, C_{16: 1} \omega 7 c$ and $C_{16: 0}$. The type strain, $\operatorname{Red} 100^{\mathrm{T}}(={ }$ NBRC $114287^{\mathrm{T}}=$ MCCC $1 \mathrm{~K} 04377^{\mathrm{T}}$ ), was isolated from paddy soil collected from Saga, Japan. The DNA G+C content of type strain is $59.7 \mathrm{~mol} \%$.

Description of Oryzomonas ruber sp. nov.: Oryzomonas ruber (ru'bra. L. fem. adj. rubra, red). Displays the following properties besides those given in the genus description. Cells are rod shaped with light curve in appearance (0.4-0.8 $\mu \mathrm{m}$ wide, $1.0-3.0 \mu \mathrm{m}$ long) and motile with peritrichous flagella. Strains display good growth on R2A agar supplemented with 5-20 mM fumarate and freshwater medium. Growth occurs at $16-40{ }^{\circ} \mathrm{C}$ (optimum, 30-33 ${ }^{\circ} \mathrm{C}$ ), at pH 5.0-7.5 (optimum, 5.5-6.5), and with $0 \%-0.5 \%(w / v) \mathrm{NaCl}$ (optimum, $0 \%-0.1 \%$ ). Can also utilize mannitol, lactate, nicotinate, casamino acid, ethanol, glutamine, arginine, serine, and proline as electron donors in the presence of Fe(III)-NTA as electron acceptor, but not phenol, isopropanol, benzyl alcohol, butanol, benzaldehyde or toluene. Can also utilize Fe(III)-EDTA, Fe(III) pyrophosphate, $\mathrm{MnO}_{2}$ and nitrate as electron acceptor in the presence of acetate as electron donor, but not sulfur. Alkaline phosphatase, naphthol-AS-BI-phosphohydrolase, acid phosphatase and leucine arylamidase activities were present but esterase (C4), trypsin, lipase (C14), valine arylamidase, esteraselipase (C8), cystine arylamidase, $\alpha$-chymotrypsin, $\alpha$-fucosidase, $\alpha$-glucosidase, $\alpha$-galactosidase, $\alpha$-mannosidase, $\beta$-glucuronidase, $\beta$-galactosidase, $\beta$-glucosidase, and $\mathrm{N}$-acetyl- $\beta$-glucosaminidase activities are absent. The predominant fatty acids are iso- $C_{15: 0}, C_{16: 1} \omega 7 c$ and $C_{16: 0}$. The type strain, $\operatorname{Red} 88^{\mathrm{T}}\left(=\mathrm{MCCC} 1 \mathrm{~K} 03694^{\mathrm{T}}=\mathrm{JCM}\right.$ $33033^{\mathrm{T}}$ ), was isolated from sediment of a pond in Niigata, Japan. The DNA G+C content of type strain is $58.4 \mathrm{~mol} \%$.

Supplementary Materials: The following are available online at http:/www.mdpi.com/2076-2607/8/5/634/s1. Four supplementary tables and eight supplementary figures are in the online Supplementary Material. Table S1. The 16S rRNA gene similarities (\%) between the three novel strains and other type strains in the family Geobacteraceae; Table S2. Annotated genes involved in ferric reduction of the three novel species; Table S3. Annotated genes involved in pilin synthesis of the three novel species; Table S4. The assembly accession numbers and genome size of the reference strains for genomic comparison. Figure S1. The geographical map of the sampling sites; Figure S2. 
Difference spectrum of whole cells for the four analyzed strains in the wavelength range of 400-800 nm; Figure S3. Phylogenetic tree (ML) of strains Red $96^{\mathrm{T}}$, Red $100^{\mathrm{T}}$, Red $88^{\mathrm{T}}$, and representatives in the order Desulfuromonadales based on 16S rRNA sequence divergence; Figure S4. Phylogenetic tree (MP) of strains $\operatorname{Red} 96^{\mathrm{T}}, \operatorname{Red} 100^{\mathrm{T}}, \operatorname{Red} 88^{\mathrm{T}}$, and representatives in the order Desulfuromonadales based on $16 \mathrm{~S}$ rRNA sequence divergence; Figure S5. The gene proportion of different functional categories for the three isolated strains with RAST server; Figure S6. The gene proportion of different functional categories for the three isolated strains with the eggNOG database; Figure S7. The gene proportion of different functional categories for the three isolated strains with the KEGG database; Figure S8. Agarose gel-electrophoresis with rep-PCR and RAPD patterns of strains $\operatorname{Red} 88^{\mathrm{T}}$, $\operatorname{Red} 96^{\mathrm{T}}$, and $\operatorname{Red} 100^{\mathrm{T}}$.

Author Contributions: Z.X., Y.M., K.S., and H.I. designed the research; Y.M., H.I., and Y.S. collected soil samples from different fields; K.K. and H.I. performed isolation experiment; Z.X. performed phenotypic, chemotaxonomic and genomic analyses; C.H. analysed fatty acid profiles; N.U. took the TEM images; Z.X., Y.M., and H.I. wrote the manuscript; Z.X., Y.M., K.S., and H.I. edited the manuscript. All authors have read and agreed to the published version of the manuscript.

Funding: This study was supported by JSPS KAKENHI Grant Numbers JP18K19165, JP18K14366, and JP17H01464 Japan, and the Canon Foundation. ZX thanks the financial support by the China Scholarship Council (CSC).

Acknowledgments: We thank Kensuke Igarashi, Haruka Ooi, and Yumi Sugisawa of the National Institute of Advanced Industrial Science and Technology (AIST) for their technical supports and Aharon Oren of Hebrew University of Jerusalem (Jerusalem, Israel) for helpful comments on nomenclature.

Conflicts of Interest: The authors declare that they have no conflict of interest. The funders had no role in the design of the study; in the collection, analyses, or interpretation of data; in the writing of the manuscript, or in the decision to publish the results.

\section{Appendix A}

$16 \mathrm{~S}$ rRNA gene, rpoB, recA, fus $A$, and nifD sequences were deposited in the GenBank database under the following numbers. 16S rRNA gene sequences: Red96 ${ }^{\mathrm{T}}$-MK334373, Red100 ${ }^{\mathrm{T}}$-MK334374, Red88 ${ }^{\mathrm{T}}$-MK334372; rpoB sequences: Red96 ${ }^{\mathrm{T}}$-MN508201, Red100 ${ }^{\mathrm{T}}$-MN508202, Red88 ${ }^{\mathrm{T}}$-MN508200; recA sequences: $\operatorname{Red}^{\mathrm{T}}{ }^{\mathrm{T}}$-MN514864, Red100 ${ }^{\mathrm{T}}$-MN514864, Red88 ${ }^{\mathrm{T}}$-MN514864; fusA sequences: Red96 ${ }^{\mathrm{T}}$-MK448247, Red100 ${ }^{\mathrm{T}}-\mathrm{MK} 448248, \operatorname{Red}^{\mathrm{T}} 8^{\mathrm{T}}$-MK448246; nifD sequences: Red96 ${ }^{\mathrm{T}}$-MN514862, Red100 - MN514863, Red88 ${ }^{\mathrm{T}}$-MN514861; gyrB sequences: Red96 ${ }^{\mathrm{T}}-\mathrm{MN} 508204, \operatorname{Red} 100^{\mathrm{T}}-\mathrm{MN508205}$, Red $88^{\mathrm{T}}$-MN508203.

The genomes of strains $\operatorname{Red} 96^{\mathrm{T}}, \operatorname{Red} 100^{\mathrm{T}}$ and $\operatorname{Red} 88^{\mathrm{T}}$ were deposited at DDBJ/ENA/NCBI under the accessions VZQZ00000000, VZRA00000000, and SRSD00000000, respectively.

\section{References}

1. Röling, W.F.M. The Family Geobacteraceae. In The Prokaryotes; Rosenberg, E., DeLong, E.F., Lory, S., Stackebrandt, E., Thompson, F., Eds.; Springer: Heidelberg, Germany, 2014; pp. 157-172.

2. Xu, Z.; Masuda, Y.; Itoh, H.; Ushijima, N.; Shiratori, Y.; Senoo, K. Geomonas edaphica sp. nov., Geomonas ferrireducens sp. nov., Geomonas terrae sp. nov., four ferric-reducing bacteria isolated from paddy soil, and reclassification of three species of the genus Geobacter as members of the genus Geomonas gen. nov. Front. Microbiol. 2019, 10, 2201. [CrossRef] [PubMed]

3. Lovley, D.R.; Giovannoni, S.J.; White, D.C.; Champine, J.E.; Phillips, E.J.P.; Gorby, Y.A.; Goodwin, S. Geobacter metallireducens gen. nov. sp. nov., a microorganism capable of coupling the complete oxidation of organic compounds to the reduction of iron and other metals. Arch. Microbiol. 1993, 159, 336-344. [CrossRef] [PubMed]

4. Lovley, D.R.; Ueki, T.; Zhang, T.; Malvankar, N.S.; Shrestha, P.M.; Flanagan, K.A.; Aklujkar, M.; Butler, J.E.; Giloteaux, L.; Rotaru, A.E.; et al. Geobacter: The microbe electric's physiology, ecology, and practical applications. Adv. Microb. Physiol. 2011, 59, 1-100. [CrossRef] [PubMed]

5. Viulu, S.; Nakamura, K.; Okada, Y.; Saitou, S.; Takamizawa, K. Geobacter luticola sp. nov., an Fe (III)-reducing bacterium isolated from lotus field mud. Int. J. Syst. Evol. Microbiol. 2013, 2, 442-448. [CrossRef]

6. Zhou, S.; Yang, G.; Lu, Q.; Wu, M. Geobacter soli sp. nov., a dissimilatory Fe(III)-reducing bacterium isolated from forest soil. Int. J. Syst. Evol. Microbiol. 2014, 64, 3786-3791. [CrossRef] 
7. Holmes, D.E.; Giloteaux, L.; Chaurasia, A.K.; Williams, K.H.; Luef, B.; Wilkins, M.J.; Wrighton, K.C.; Thompson, C.A.; Comolli, L.R.; Lovley, D.R. Evidence of Geobacter-associated phage in a uranium-contaminated aquifer. ISME J. 2015, 9, 333-346. [CrossRef]

8. Hori, T.; Müller, A.; Igarashi, Y.; Conrad, R.; Friedrich, M.W. Identification of iron-reducing microorganisms in anoxic rice paddy soil by ${ }^{13} \mathrm{C}$-acetate probing. ISME J. 2010, 4, 267-278. [CrossRef]

9. Li, Z.; Suzuki, D.; Zhang, C.; Yang, S.; Nan, J.; Yoshida, N.; Wang, A.; Katayama, A. Anaerobic 4-chlorophenol mineralization in an enriched culture under iron-reducing conditions. J. Biosci. Bioeng. 2014, 118, 529-532. [CrossRef]

10. Ding, L.J.; Su, J.Q.; Xu, H.J.; Jia, Z.J.; Zhu, Y.G. Long-term nitrogen fertilization of paddy soil shifts iron-reducing microbial community revealed by RNA- ${ }^{13} \mathrm{C}$-acetate probing coupled with pyrosequencing. ISME J. 2015, 9, 721-734. [CrossRef]

11. Itoh, H.; Ishii, S.; Shiratori, Y.; Oshima, K.; Otsuka, S.; Hattori, M.; Senoo, K. Seasonal transition of active bacterial and archaeal communities in relation to water management in paddy soils. Microbes Environ. 2013, 28, 370-380. [CrossRef]

12. Kim, Y.; Liesack, W. Differential assemblage of functional units in paddy soil microbiomes. PLoS ONE 2015, 10, e0122221. [CrossRef] [PubMed]

13. Masuda, Y.; Itoh, H.; Shiratori, Y.; Isobe, K.; Otsuka, S.; Senoo, K. Predominant but previously-overlooked prokaryotic drivers of reductive nitrogen transformation in paddy soils, revealed by metatranscriptomics. Microbes Environ. 2017, 32, 180-183. [CrossRef] [PubMed]

14. Tipayno, S.C.; Truu, J.; Samaddar, S.; Truu, M.; Preem, J.K.; Oopkaup, K.; Espenberg, M.; Chatterjee, P.; Kang, Y.; Kim, K.; et al. The bacterial community structure and functional profile in the heavy metal contaminated paddy soils, surrounding a nonferrous smelter in South Korea. Ecol. Evol. 2018, 8, 6157-6168. [CrossRef] [PubMed]

15. Holmes, D.E.; Shrestha, P.M.; Walker, D.J.F.; Dang, Y.; Nevin, K.P.; Woodard, T.L.; Lovley, D.R. Metatranscriptomic evidence for direct interspecies electron transfer between Geobacter and Methanothrix species in methanogenic rice paddy soils. Appl. Environ. Microbiol. 2017, 83, e00223-17. [CrossRef]

16. Hori, T.; Aoyagi, T.; Itoh, H.; Narihiro, T.; Oikawa, A.; Suzuki, K.; Ogata, A.; Friedrich, M.W.; Conrad, R.; Kamagata, Y. Isolation of microorganisms involved in reduction of crystalline iron(III) oxides in natural environments. Front. Microbiol. 2015, 6, 386. [CrossRef]

17. Li, H.; Su, J.Q.; Yang, X.R.; Zhou, G.W.; Lassen, S.B.; Zhu, Y.G. RNA stable isotope probing of potential feammox population in paddy soil. Environ. Sci. Technol. 2019, 53, 4841-4849. [CrossRef]

18. Masuda, Y.; Itoh, H.; Shiratori, Y.; Senoo, K. Metatranscriptomic insights into microbial consortia driving methane metabolism in paddy soils. Soil Sci. Plant. Nutr. 2018, 64, 455-464. [CrossRef]

19. Deng, D.; Zhang, Y.; Liu, Y. A Geobacter strain isolated from rice paddy soil with higher bioelectricity generation capability in comparison to Geobacter sulfurreducens PCA. RSC Adv. 2015, 5, 43978-43989. [CrossRef]

20. Ohtsuka, T.; Yamaguchi, N.; Makino, T.; Sakurai, K.; Kimura, K.; Kudo, K.; Homma, E.; Dong, D.T.; Amachi, S. Arsenic dissolution from Japanese paddy soil by a dissimilatory arsenate-reducing bacterium Geobacter sp. OR-1. Environ. Sci. Technol. 2013, 47, 6263-6271. [CrossRef]

21. Willems, A. The taxonomy of rhizobia: An overview. Plant. Soil 2006, 287, 3-14. [CrossRef]

22. Lagier, J.C.; Dubourg, G.; Million, M.; Cadoret, F.; Bilen, M.; Fenollar, F.; Rolain, J.M.; Fournier, P.E.; Raoult, D. Culturing the human microbiota and culturomics. Nat. Rev. Microbiol. 2018, 16, 540-550. [CrossRef]

23. Nevin, K.P.; Holmes, D.E.; Woodard, T.L.; Hinlein, E.S.; Ostendorf, D.W.; Lovley, D.R. Geobacter bemidjiensis sp. nov. and Geobacter psychrophilus sp. nov., two novel Fe(III)-reducing subsurface isolates. Int. J. Syst. Evol. Microbiol. 2005, 55, 1667-1674. [CrossRef] [PubMed]

24. Onley, J.R.; Ahsan, S.; Sanford, R.A. Denitrification by Anaeromyxobacter dehalogenans, a common soil bacterium lacking the nitrite reductase genes nirS and nirK. Appl. Environ. Microbiol. 2018, 84, 1-14. [CrossRef]

25. Ashida, N.; Ishii, S.; Hayano, S.; Tago, K.; Tsuji, T.; Yoshimura, Y.; Otsuka, S.; Senoo, K. Isolation of functional single cells from environments using a micromanipulator: Application to study denitrifying bacteria. Appl. Microbiol. Biotechnol. 2010, 85, 1211-1217. [CrossRef] [PubMed]

26. Yoon, S.H.; Ha, S.M.; Kwon, S.; Lim, J.; Kim, Y.; Seo, H.; Chun, J. Introducing EzBioCloud: A taxonomically united database of $16 \mathrm{~S}$ rRNA gene sequences and whole-genome assemblies. Int. J. Syst. Evol. Microbiol. 2017, 67, 1613-1617. [CrossRef] 
27. Kumar, S.; Stecher, G.; Tamura, K. MEGA7: Molecular evolutionary genetics analysis version 7.0 for bigger datasets. Mol. Biol. Evol. 2016, 33, 1870-1874. [CrossRef]

28. Glaeser, S.P.; Kämpfer, P. Multilocus sequence analysis (MLSA) in prokaryotic taxonomy. Syst. Appl. Microbiol. 2015, 38, 237-245. [CrossRef]

29. Holmes, D.E.; Nevin, K.P.; Lovley, D.R. Comparison of $16 \mathrm{~S} r R N A$, nifD, $r e c A, g y r B, r p o B$ and fus $A$ genes within the family Geobacteraceae fam. nov. Int. J. Syst. Evol. Microbiol. 2004, 54, 1591-1599. [CrossRef]

30. Zerbino, D.R.; Birney, E. Velvet: Algorithms for de novo short read assembly using de Bruijn graphs. Genome Res. 2008, 18, 821-829. [CrossRef]

31. Boetzer, M.; Henkel, C.V.; Jansen, H.J.; Butler, D.; Pirovano, W. Scaffolding pre-assembled contigs using SSPACE. Bioinformatics 2010, 27, 578-579. [CrossRef]

32. Boetzer, M.; Pirovano, W. Toward almost closed genomes with GapFiller. Genome Biol. 2012, 13, R56. [CrossRef] [PubMed]

33. Aziz, R.K.; Bartels, D.; Best, A.A.; DeJongh, M.; Disz, T.; Edwards, R.A.; Formsma, K.; Gerdes, S.; Glass, E.M.; Kubal, M.; et al. The RAST Server: Rapid annotations using subsystems technology. BMC Genom. 2008, 9, 75. [CrossRef] [PubMed]

34. Kanehisa, M.; Sato, Y.; Morishima, K. BlastKOALA and GhostKOALA: KEGG tools for functional characterization of genome and metagenome sequences. J. Mol. Biol. 2016, 428, 726-731. [CrossRef] [PubMed]

35. Huerta-Cepas, J.; Forslund, K.; Coelho, L.P.; Szklarczyk, D.; Jensen, L.J.; von Mering, C.; Bork, P. Fast genome-wide functional annotation through orthology assignment by eggNOG-Mapper. Mol. Biol. Evol. 2017, 34, 2115-2122. [CrossRef] [PubMed]

36. Richter, M.; Rosselló-Móra, R.; Oliver Glöckner, F.; Peplies, J. JSpeciesWS: A web server for prokaryotic species circumscription based on pairwise genome comparison. Bioinformatics 2016, 32, 929-931. [CrossRef] [PubMed]

37. Meier-Kolthoff, J.P.; Auch, A.F.; Klenk, H.P.; Göker, M. Genome sequence-based species delimitation with confidence intervals and improved distance functions. BMC Bioinform. 2013, 14, 60. [CrossRef]

38. Konstantinidis, K.T.; Tiedje, J.M. Towards a genome-based taxonomy for prokaryotes. J. Bacteriol. 2005, 187, 6258-6264. [CrossRef]

39. Qin, Q.L.; Xie, B.B.; Zhang, X.Y.; Chen, X.L.; Zhou, B.C.; Zhou, J.; Oren, A.; Zhang, Y.Z. A proposed genus boundary for the prokaryotes based on genomic insights. J. Bacteriol. 2014, 196, 2210-2215. [CrossRef]

40. Na, S.I.; Kim, Y.O.; Yoon, S.H.; Ha, S.; Baek, I.; Chun, J. UBCG: Up-to-date bacterial core gene set and pipeline for phylogenomic tree reconstruction. J. Microbiol. 2018, 56, 280-285. [CrossRef]

41. Alikhan, N.F.; Petty, N.K.; Zakour, N.L.B.; Beatson, S.A. BLAST Ring Image Generator (BRIG): Simple prokaryote genome comparisons. BMC Genomics 2011, 12, 402. [CrossRef]

42. Darling, A.C.E.; Mau, B.; Blattner, F.R.; Perna, N.T. Mauve: Multiple alignment of conserved genomic sequence with rearrangements. Genome Res. 2004, 14, 1394-1403. [CrossRef] [PubMed]

43. Guy, L.; Kultima, J.R.; Andersson, S.G.E. genoPlotR: Comparative gene and genome visualization in R. Bioinformatics 2010, 26, 2334-2335. [CrossRef] [PubMed]

44. Page, A.J.; Cummins, C.A.; Hunt, M.; Wong, V.K.; Reuter, S.; Holden, M.T.G.; Fookes, M.; Falush, D.; Keane, J.A.; Parkhill, J. Roary: Rapid large-scale prokaryote pan genome analysis. Bioinformatics 2015, 31, 3691-3693. [CrossRef]

45. Seemann, T. Prokka: Rapid prokaryotic genome annotation. Bioinformatics 2014, 30, 2068-2069. [CrossRef] [PubMed]

46. Yu, K.; Pauls, K.P. Optimization of the PCR program for RAPD analysis. Nucleic Acids Res. 1992, $20,2606$. [CrossRef] [PubMed]

47. Versalovic, J.; Schneider, M.; De Bruijn, F.J.; Lupski, J.R. Genomic fingerprinting of bacteria using repetitive sequence-based polymerase chain reaction. Methods Mol. Cell. Biol. 1994, 5, 25-40.

48. Kuykendall, L.D.; Roy, M.A.; O'neill, J.J.; Devine, T.E. Fatty acids, antibiotic resistance, and deoxyribonucleic acid homology groups of Bradyrhizobium japonicum. Int. J. Syst. Bacteriol. 1988, 38, 358-361. [CrossRef]

49. Gunina, A.; Dippold, M.A.; Glaser, B.; Kuzyakov, Y. Fate of low molecular weight organic substances in an arable soil: From microbial uptake to utilisation and stabilisation. Soil Biol. Biochem. 2014, 77, 304-313. [CrossRef] 
50. Bligh, E.G.; Dyer, W.J. A rapid method of total lipid extraction and purification. Can. J. Biochem. Physiol. 1959, 37, 911-917. [CrossRef]

51. Afkar, E.; Fukumori, Y. Purification and characterization of triheme cytochrome $\mathrm{c} 7$ from the metal-reducing bacterium, Geobacter metallireducens. FEMS Microbiol. Lett. 1999, 175, 205-210. [CrossRef]

52. Schink, B. Fermentation of 2,3-butanediol by Pelobacter carbinolicus sp. nov. and Pelobacter propionicus sp. nov., and evidence for propionate formation from $C_{2}$ compounds. Arch. Microbiol. 1984, 137, 33-41. [CrossRef]

53. Sung, Y.; Fletcher, K.E.; Ritalahti, K.M.; Apkarian, R.P.; Ramos-Hernández, N.; Sanford, R.A.; Mesbah, N.M.; Löffler, F.E. Geobacter lovleyi sp. nov. strain SZ, a novel metal-reducing and tetrachloroethene-dechlorinating bacterium. Appl. Environ. Microbiol. 2006, 72, 2775-2782. [CrossRef] [PubMed]

54. Nevin, K.P.; Holmes, D.E.; Woodard, T.L.; Covalla, S.F.; Lovley, D.R. Reclassification of Trichlorobacter thiogenes as Geobacter thiogenes comb. nov. Int. J. Syst. Evol. Microbiol. 2007, 57, 463-466. [CrossRef] [PubMed]

55. Coates, J.D.; Bhupathiraju, V.K.; Achenbach, L.A.; Mcinerney, M.J.; Lovley, D.R. Geobacter hydrogenophilus, Geobacter chapellei and Geobacter grbiciae, three new, strictly anaerobic, dissimilatory Fe(III)-reducers. Int. J. Syst. Evol. Microbiol. 2001, 335182, 581-588. [CrossRef]

56. Yarza, P.; Yilmaz, P.; Pruesse, E.; Glöckner, F.O.; Ludwig, W.; Schleifer, K.H.; Whitman, W.B.; Euzéby, J.; Amann, R.; Rosselló-Móra, R. Uniting the classification of cultured and uncultured bacteria and archaea using 16S rRNA gene sequences. Nat. Rev. Microbiol. 2014, 12, 635. [CrossRef] [PubMed]

57. Shi, L.; Dong, H.; Reguera, G.; Beyenal, H.; Lu, A.; Liu, J.; Yu, H.Q.; Fredrickson, J.K. Extracellular electron transfer mechanisms between microorganisms and minerals. Nat. Rev. Microbiol. 2016, 14, 651-662. [CrossRef]

58. Shi, L.; Fredrickson, J.K.; Zachara, J.M. Genomic analyses of bacterial porin-cytochrome gene clusters. Front. Microbiol. 2014, 5, 657. [CrossRef]

59. Cai, X.; Huang, L.; Yang, G.; Yu, Z.; Wen, J.; Zhou, S. Transcriptomic, proteomic, and bioelectrochemical characterization of an exoelectrogen Geobacter soli grown with different electron acceptors. Front. Microbiol. 2018, 9, 1075. [CrossRef]

60. Holmes, D.E.; Dang, Y.; Walker, D.J.F.; Lovley, D.R. The electrically conductive pili of Geobacter species are a recently evolved feature for extracellular electron transfer. Microb. genomics 2016, 2, e000072. [CrossRef]

61. Lovley, D.R.; Walker, D. Geobacter protein nanowires. Front. Microbiol. 2019, 10, 2078. [CrossRef]

62. Malvankar, N.S.; Lovley, D.R. Microbial nanowires for bioenergy applications. Curr. Opin. Biotechnol. 2014, 27, 88-95. [CrossRef] [PubMed]

63. Walker, D.J.; Adhikari, R.Y.; Holmes, D.E.; Ward, J.E.; Woodard, T.L.; Nevin, K.P.; Lovley, D.R. Electrically conductive pili from pilin genes of phylogenetically diverse microorganisms. ISME J. 2018, 12, 48-58. [CrossRef] [PubMed]

64. Chun, J.; Oren, A.; Ventosa, A.; Christensen, H.; Arahal, D.R.; da Costa, M.S.; Rooney, A.P.; Yi, H.; Xu, X.W.; Meyer, S.D.; et al. Proposed minimal standards for the use of genome data for the taxonomy of prokaryotes. Int. J. Syst. Evol. Microbiol. 2018, 68, 461-466. [CrossRef] [PubMed]

65. Richter, M.; Rosselló-Móra, R. Shifting the genomic gold standard for the prokaryotic species definition. Proc. Natl. Acad. Sci. USA. 2009, 106, 19126-19131. [CrossRef]

66. Luo, C.; Rodriguez-R, L.M.; Konstantinidis, K.T. MyTaxa: An advanced taxonomic classifier for genomic and metagenomic sequences. Nucleic Acids Res. 2014, 42, e73. [CrossRef]

(C) 2020 by the authors. Licensee MDPI, Basel, Switzerland. This article is an open access article distributed under the terms and conditions of the Creative Commons Attribution (CC BY) license (http://creativecommons.org/licenses/by/4.0/). 